\title{
The influence of Standard German on the vowels and diphthongs of West Central Bavarian
}

\author{
Katrin Wolfswinkler \\ Institute of Phonetics \& Speech Processing (IPS), Ludwig-Maximilians University of Munich, \\ Munich, Germany \\ katrin@phonetik.uni-muenchen.de \\ Jonathan Harrington \\ Institute of Phonetics \& Speech Processing (IPS), Ludwig-Maximilians University of Munich, \\ Munich, Germany \\ jmh@phonetik.uni-muenchen.de
}

\begin{abstract}
The spoken accent of children is strongly influenced by those of their peers but how rapidly do they adapt to sound changes in progress? We addressed this issue in an acoustic analysis of child and adult vowels of West Central Bavarian (WCB) that may be subject to an increasing influence by the Standard German (SG) variety. The study was a combination of longitudinal and apparent-time analyses: re-recordings from $20 \mathrm{WCB}$ children in their first, second and third years of primary school at two schools in rural Bavaria were compared with those of $21 \mathrm{WCB}$ adult speakers from the same area. The question was whether the children's pronunciation diverged from the adults' pronunciation and increasingly so in their second and third years. Participants produced stressed vowels in isolated mostly trochaic words in which WCB vs. SG differences were expected. Both adult/child and longitudinal changes in the direction of the standard were found in the children's tendency towards a merger of two open vowels and a collapse of a long/short consonant contrast, neither of which exists in SG. There was some evidence that, unlike the adults, the children were beginning to develop tensity (= tenseness) and rounding contrasts, which occur in SG but not WCB. There were no observed changes to the pattern of opening and closing diphthongs, which differ markedly between the two varieties. The general conclusion is that WCB change is most likely to occur as a consequence of exaggerating phonetic variation that already happens to be in the direction of the standard.
\end{abstract}

\section{Introduction}

The present study is concerned with a description of the vowel system of the West Central Bavarian (WCB) dialect and the changes that may be occurring in this dialect as assessed by a combined longitudinal and apparent-time acoustic analysis of WCB children and adults. We consider first some general observations about dialects and the standard variety in German in Section 1.1. This is followed by a summary of the main systemic differences and equivalences between WCB and Standard German (SG) monophthongs and diphthongs in Section 1.2, also taking into account some relevant phonetic realisational differences between these varieties. This comparison between the varieties in Section 1.2 forms the basis for predictions about changes in progress to WCB in Section 1.3, under the assumption that WCB is being increasingly influenced by the standard variety. 
The study had four aims. The first was to document the phonological and phonetic correspondences between the vowels of Standard German and those of West Central Bavarian (Sections 1.1 and 1.2). This purpose of doing so was to clarify the nature of the synchronic systemic differences between these varieties - i.e. those in which vowel phonemes contrast different sets of lexical items - and to separate these systemic differences at the phonological level as far as possible from phonetic realisational differences between the varieties. This aim is then one of language (or in this case) dialect documentation. The second aim was concerned with dialect contact: that is, to make use of these documented systemic and phonetic differences in order to predict the possible changes that should occur in WCB, under the assumption that this variety is being influenced by the standard (Section 1.3). The third aim (Sections 2 and 3) was concerned with sound change and specifically with analysing whether WCB like many other German varieties is changing in the direction of the standard. The analysis was of production data using acoustic techniques in both an apparent-time study in which adults were compared with primary school children and a longitudinal study in which changes were analysed in the same children longitudinally over three years. The fourth aim was to determine whether the rate of sound change was affected by social and phonological properties of the speech sounds that were investigated, in particular whether sounds that are salient markers of a dialect are less prone to change (Trudgill 1986, Auer, Barden \& Grosskopf 1998, Siegel 2010) and to assess whether sound changes that result in mergers as opposed to new contrasts progress at different rates (Chambers 1992, Kerswill 1996, Evans \& Iverson 2007).

\subsection{West Central Bavarian and its relationship to Standard German}

Contemporary Standard German has evolved over several centuries in a process of gradual linguistic accommodation between diverse regional dialects. These dialects exist until today and are typically defined as being spoken within a certain geographical area, irrespective of their social status (Zehetner 1985). They range on a linguistic continuum between basic dialects and the spoken standard with various stages of mixture in between, which are neither dialect-free standard nor pure dialect (Veith 2005, Rowley 2011).

Basic dialects at the one end of this continuum diverge most from the standard. Their communicative range is restricted as they tend to have a distinct grammar and phonology (Chambers \& Trudgill 1998) and are therefore often mutually unintelligible (Leopold 1959, Rues et al. 2007). The standard language on the other end of the continuum has a geographically broader communicative range and, partly because it is the language used in schools and the media, it often has an increasingly larger influence on dialects (Besch 1983, Zehetner 1985). Between these two endpoints of a basic dialect and the standard language, a third level, referred to as regional variety, is usually distinguished which is neither dialect nor standard (Rowley 2011). German regional varieties have characteristics of a dialect but are in their local and communicative narrowness above the basic dialects and can vary until they are close to the standard (Zehetner 1989). Regional varieties are mostly occurrences of language contact between Standard German with the spoken dialects. That is, whereas regional varieties are highly influenced by the standard, basic dialects show the greatest geographical differences and the least similarity with the standard (König 1994).

The degree to which a basic dialect or regional variety is spoken also differs from region to region. While in Northern Germany basic dialects are rarely spoken, they are still common in the South (Kleber 2011). Moreover, Standard German pronunciation is almost always influenced to some extent by the regional background of a speaker (Wiese 1996).

The increasing spread of, and contact with, SG even in rural areas has often resulted in a shift of certain dialectal features in the direction of SG (Reiffenstein 1976, Scheuringer 1990). Most of the experimental evidence for the influence of SG on German dialects is based on quite recent apparent-time studies comparing old vs. young speakers of a given population. For example, word pairs in East Franconian that differ in post-vocalic obstruent voicing in SG (e.g. leiten/leiden /laitn, laidn/ 'to lead/suffer') are homophonous with a voiced stop (both 


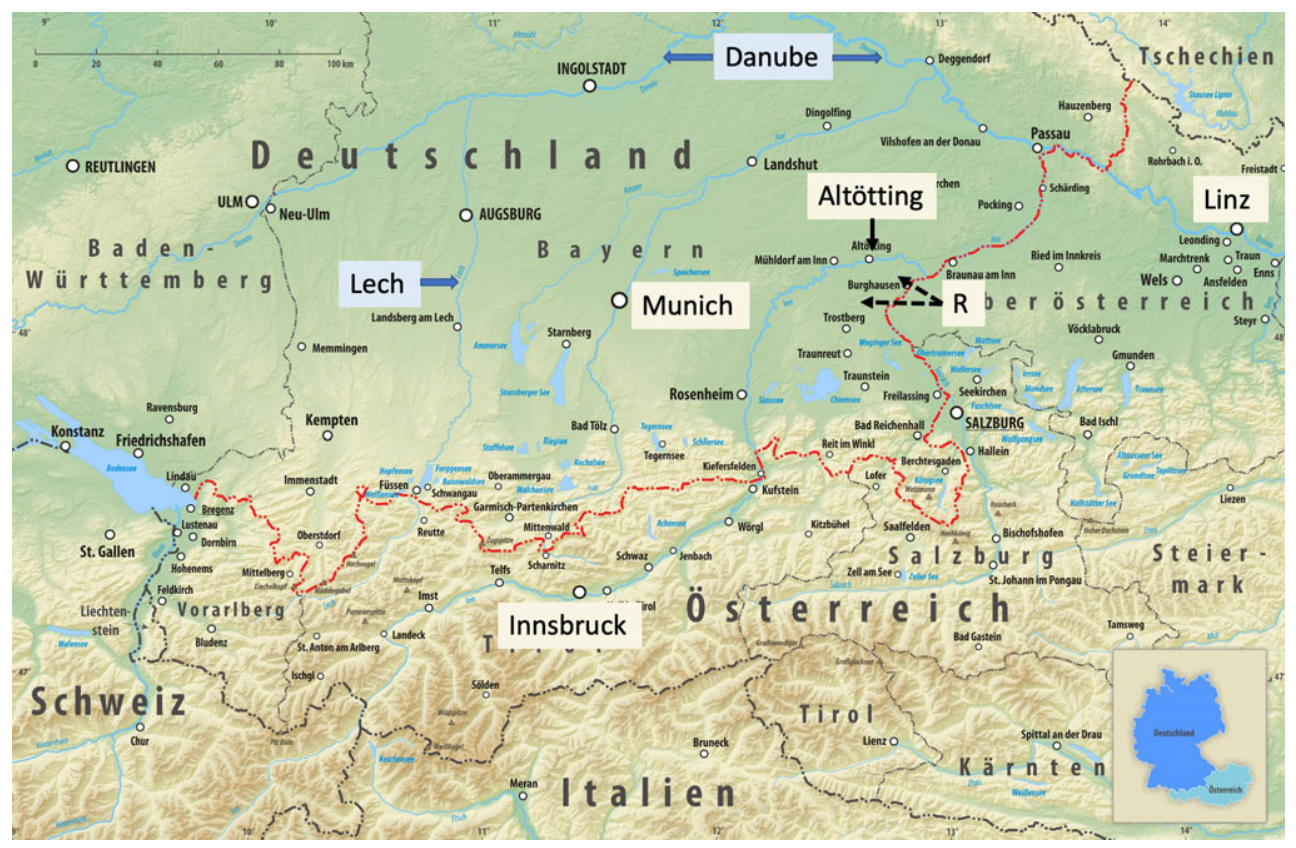

Figure 1 A map showing some defining markers of the region in which West Central Bavarian is spoken. The heads of the dashed arrows linked to $R$ mark the location of recording sites near Altötting. The dashed red line marks the border between Bavaria and Austria.

/laidn/). Müller et al. (2011) showed that such pairs were, however, only homophonous in older speakers of the dialect. Younger dialect speakers in contrast were beginning to distinguish between them, although not to the same extent as in the standard. Augsburg Swabian has $/ \int /$ in post-vocalic clusters that maps to two phonemes in SG (e.g. SG: /vest, veft/ west, wäscht 'west, washes'; both are /vest/ in Augsburg Swabian). Once again, this contrast was shown to be more marked for younger than older Augsburg participants in both production and perception but not as marked as for standard speakers (Bukmaier, Harrington \& Kleber 2014).

As discussed in further details in Section 1.2.1 below, WCB but not SG has an inverse quantity relationship in which a short vowel is followed by a long consonant and vice versa. Kleber (2017) found that this characteristic was more evident in older than in younger WCB speakers.

WCB is spoken in the south of Germany around Munich and rural areas of Bavaria (Figure 1). ${ }^{1}$ WCB extends to the west to around the river Lech and to the north just beyond the Danube. To the south, WCB extends beyond the Austrian border, but not as far as Innsbruck which belongs to the South Bavarian variety. To the east, WCB also extends beyond the Austrian border where it merges with East Central Bavarian, the latter also including Linz and Vienna (Schikowski 2009, Kleber 2017).

WCB forms part of the Upper German dialects which in contrast to Central and Low German dialects were substantially affected by the Second German sound shift that took place between the years $600 \mathrm{AD}$ and $800 \mathrm{AD}$ (Kufner 1960, Kleber 2011). Moreover, WCB has preserved many sounds from Middle High German which were lost in the standard (Pascoe 1981, Zehetner 1985). In contrast to WCB, SG has been extensively conditioned by Central

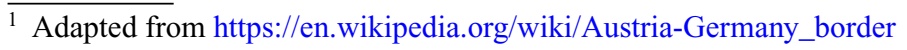


German dialects (Zehetner 1989, Schmidt 2000, Kleber 2011). For example, Luther's translation of the Bible was into a Central German variety (Kufner 1957, Zehetner 1985). These somewhat different historical developments are one of the reasons why there are not just phonetic, realisational but also many systemic (Wells 1982) differences between Standard German and WCB vowel systems.

WCB is a variety with its own lexicon, grammar and vowel system (Bannert 1973, Zehetner 1989). Dialect speakers can typically shift speech production along the standarddialect continuum depending upon their social status and relationship to the hearer. Hence, depending on the communicative situation, WCB speakers produce either a basic dialect (e.g. when talking to family or friends) or a regional variety of the standard (e.g. with outsiders or in more formal speaking situations; Zehetner 1989). That is, while Bavarian dialect speakers can use the standard in order to be more widely understood, their pronunciation is still coloured in a way that provides strong cues to their dialect background (e.g. by the apical pronunciation of [r] typically of Bavarians speaking the standard as opposed to [ $\mathrm{\sigma}]$ produced by many northern variety speakers of the standard). Speakers from northern parts of Germany (in which speaking in dialect is less common) sometimes even confuse the Bavarian-coloured standard with the Bavarian dialect (Rowley 2011).

As mentioned above, dialect usage in the southern parts of Germany is generally very common and in rural areas more prevalent than in the cities. Even if SG is referred to as the language of the townspeople and the school (König 1994), speaking the local dialect in Bavaria is not stigmatised. Indeed, studies have found that Bavarian speakers produce local varieties with the greatest degree of proficiency than anywhere else in Germany (e.g. Institut für Demoskopie Allensbach 1998, 2008). The same studies often report that Bavarian is one of the best-liked dialects in Germany and even the most 'sexy sounding' (Rowley 2011).

In the following, we begin by outlining the main differences between the vowels of the two varieties (Section 1.2); based on these differences, we predict some likely monophthong/diphthong changes in WCB (Section 1.3), under the assumption that they are caused and/or propagated by an influence of the standard variety.

\subsection{The relationship between WCB and SG monophthongs/diphthongs}

The overview of the mappings in Figure 2 between SG and WCB for the monophthongs and diphthongs shows that SG has a more crowded monophthongal vowel space but five fewer diphthongs than WCB. The former comes about principally because SG but not WCB contrasts (i) front rounded and unrounded vowels /i y/, /I Y/, /e ø/, / $\varepsilon$ œ/ and (ii) tense/lax pairs /i I/, /e $\varepsilon /$, /a $\mathrm{e} /, / \mathrm{y} \mathrm{Y} /$, /ø œ/, /u $\mathrm{u} /$ that differ in both length and, with the exception of /a $\mathrm{e} /$, in quality (see also Hoole 1987, Harrington et al. 2011 for an articulatory analysis).

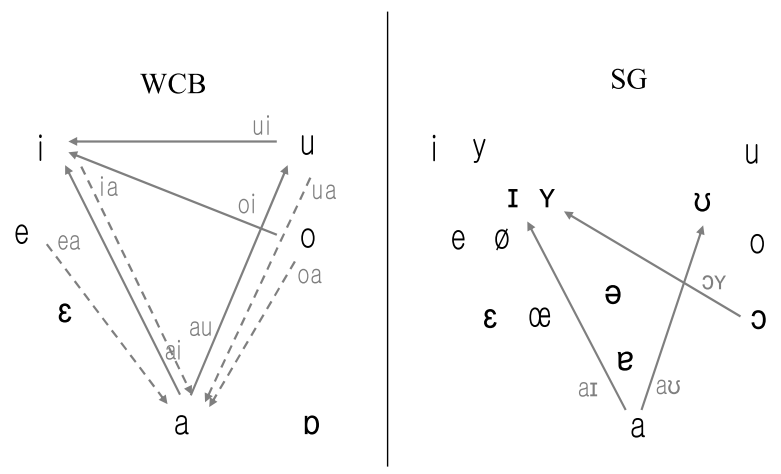

Figure 2 West Central Bavarian (WCB) and Standard Bavarian (SB) monophthong phonemes with superimposed closing/level (solid) and opening (dashed) diphthong phonemes. 


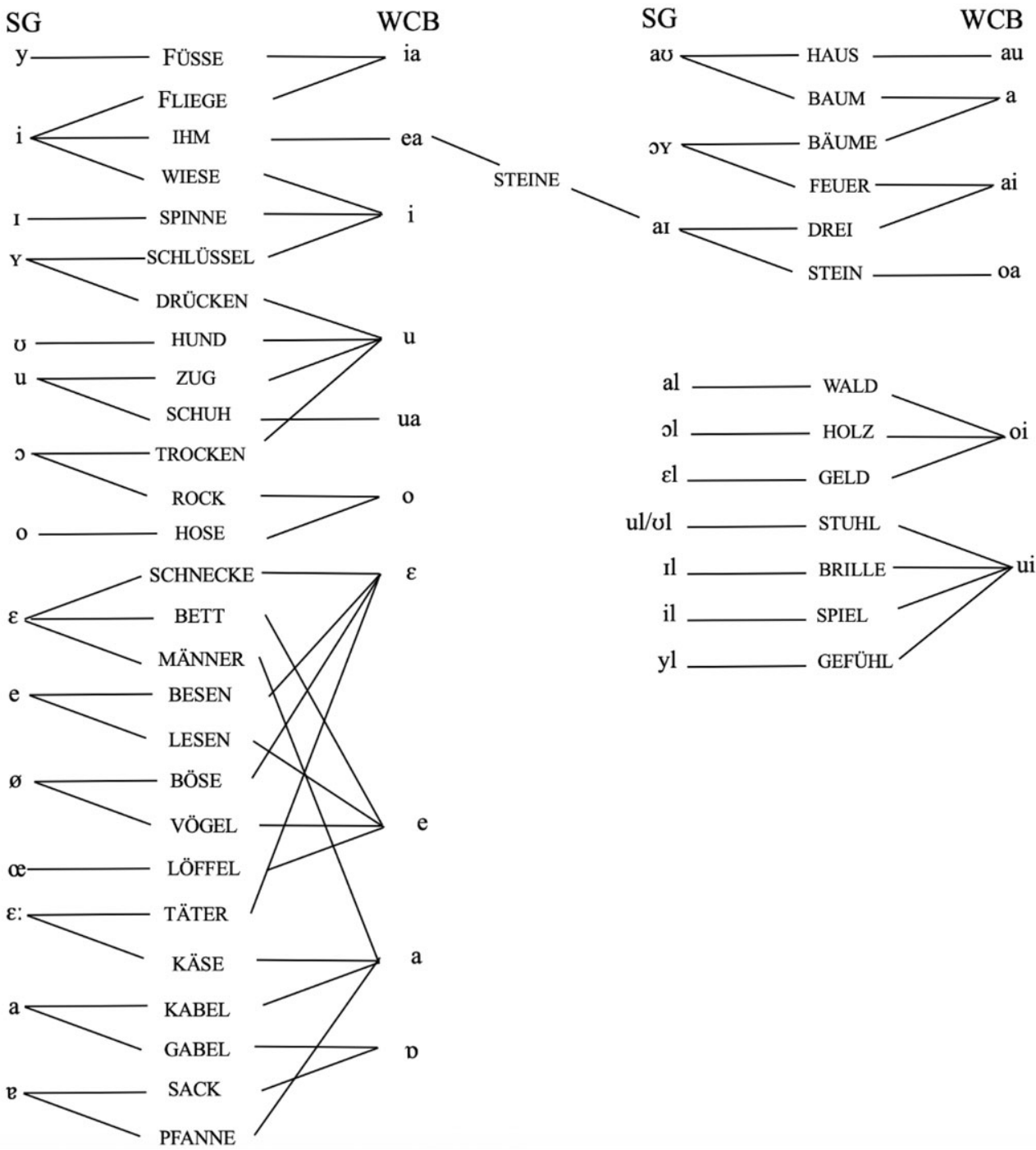

Figure 3 Association between SG and WCB vowel phonemes exemplified by LExICAL SETS (see Appendix A). Left: SG monophthongs. Right: SG diphthongs and vowels before /1/. The lines show correspondences between broad (i.e. phonemic) transcriptions. For example, the vowel phoneme in the first syllable of DRÜCKEN, HUND, ZUG, TROCKEN is $/ \mathbf{u} /$ in all four cases in WCB but /Y $\cup$ u $\mathrm{\jmath} /$, respectively, in SG.

The greater number of diphthongs in WCB is because of an additional set of opening diphthongs ${ }^{2}$ - i.e. diphthongs with a mid-high or high first component - and also because WCB vocalises domain-final /1/.

Figure 3 shows the association between SG and WCB vowel/diphthong phonemes in terms of LEXICAL SETS which stand for word classes of the same type. A lexical set and

$\overline{{ }^{2} \text { We exclude }}$ from further consideration the opening/centering diphthongs that arise in both varieties due to pre-consonantal and word-final post-vocalic /r/ vocalisation e.g. wir 'we' SG: /vIə/, WCB: /mia/. Opening diphthongs in WCB due to /r/-vocalisation all map to those that are not due to /r/-vocalisation: e.g. WCB /mia/ has the same diphthong as in WCB FÜSSE und FLIEGE (see Figure 3). 
a SG-WCB association was only included in Figure 3 if there are at least five words that match the corresponding pattern (see Appendix A for further examples). It is very clear from Figure 3, that there is no systemic equivalence (Wells 1982) between any pair of SG and WCB monophthongs or diphthongs. Some further details on the salient differences in vowels between these varieties are summarised in the following seven points below.

\subsubsection{Tensity ${ }^{3}$ and length}

As stated earlier, SG has a phonemic opposition between tense and lax vowel pairs that differ in quantity and quality. WCB on the other hand has a difference between short and long vowels that are inversely related to the length of the following consonant (Kufner 1957, 1960; Bannert 1973; Capell 1979; Seiler 2009; Kleber 2011). That is, long vowels are predictably followed by short consonants and short vowels by long consonants. ${ }^{4}$ There is, for example, a distinction between V:C [le:sn] 'to read' and VC: [mesia] 'knife' (Kufner 1957, Bannert 1976, Pascoe 1981, Scheuringer 1990). C can not only be any obstruent but also a nasal consonant (Kleber 2017). Relatively recent research by Kleber (2017) supports the conclusions in Bannert (1976) that neither vowel length nor consonant length on its own is phonemic: the phonemic opposition is instead between short vowels followed by long consonants (VC:) as opposed to long vowels followed by short consonants (V:C). The complexity here is that WCB vowel length by itself is allophonic (because it is predictable from consonant length) and so is WCB consonant length (because it is predictable from vowel length). However, the type of complementary length is unpredictable which means that words must be marked in the lexicon for whether they are of the form VC: or $\mathrm{V}: \mathrm{C}$.

There is no systemic equivalence between tense/lax pairs in SG and long/short vowels in WCB. For example, the first vowels in Spinne 'spider' and Tisch 'table' are both / $\mathrm{I} /$ in SG; but in WCB the former contains a short [i] (followed by a long [n]) and the latter a long [i:] (followed by a short [S]).

\subsubsection{SG front rounded vowels}

Whereas SG has a phonemic opposition in the front vowel set between unrounded /i I e $\varepsilon /$ and rounded /y Y $\varnothing \propto /$, there is no such rounding contrast in WCB (Wiesinger 1990, Schikowski 2009). At around the end of the 13th century, WCB rounded front vowels were unrounded and coalesced with unrounded front vowels of the same height (Kufner 1957, Merkle 1976, Zehetner 1985). As a consequence, whereas SG distinguishes between unrounded and rounded front vowels of same phonetic height (/i/ vs. /y/, /I/ vs. /Y/, /e/ vs. $\varnothing /, / \varepsilon /$ vs. /œ/) WCB does not. As Figure 3 shows, it is not the case that the contrasts in SG \pm round are simply neutralised in WCB. For example, WCB /i y/ in the lexical sets WIESE and FÜSSE correspond to /i ia/ in WCB. But as discussed in Section 1.2.3, there is no systemic equivalence. Thus, while the SG/I Y/ contrast can correspond to WCB / $\mathrm{i} u$ / in SPINNE and DRÜCKEN, respectively, WCB /u/ also maps to SG/u/ in ZUG.

\subsubsection{SG high vowels and WCB opening diphthongs}

SG high tense vowels /i y/ exemplified by FLIEGE and FÜSSE both map to WCB /ia/; SG /u/ exemplified by SCHUH is /ua/ in $\mathrm{WCB}^{5}$ (Kufner 1957, Wiesinger 1990). Such differences

\footnotetext{
3 Tensity is sometimes referred to as tenseness.

4 There are no phonetic voicing distinctions in WCB consonants; thus, the phonetic difference between [s] and [s:] in WCB [be:sn] and [mes:a] is in length, not voicing (Bannert 1976).

5 There is also an association from SG/U/ to WCB /ua/, which is not shown in Fig 3. because it does not seem to be productive, occurring only in three words (Futter 'fodder', Mutter 'mother', muss 'must') to our knowledge.
} 
between these varieties derive historically from changes of the MHG diphthongs ie, üe, uo that became long monophthongs in SG but were preserved as diphthongs in WCB (Mansell 1973; Zehetner 1985, 1989). Figure 3 shows that there is no systemic mapping between SG high tense vowels and WCB opening diphthongs. Thus, whereas there is an $/ \mathrm{i} \sim \mathrm{ia} / \mathrm{mapping}$ for SG WCB in FLIEGE, they both have monophthongal /i/ in WIESE. There may also be phonetic (realisational) differences between the varieties in words of the WIESE type in which both SG and WCB have monophthongs: according to Schikowski (2009), WCB /i/ is more centralised than $\mathrm{SG} / \mathrm{i} /$.

Some words exemplified by IHM, with an SG tense vowel/i/, map to a mid-high opening /ea/ diphthong in WCB. In all IHM words, SG/i/ and the corresponding WCB /ea/ are closed by a nasal consonant (Appendix A). The historical evolution of the vowel exemplified by IHM into WCB /ea/ rather than /ia/ could be explained with reference to studies showing that a nasal often causes a preceding high vowel to be lowered both synchronically and diachronically (Beddor 1982, Hajek 1997, Sampson 1999, Carignan 2018). WCB /ia/ can nevertheless occur before a nasal consonant, but only in words where SG and WCB differ in whether or not there is an intervening oral stop. Thus, SG /fli:gy/ 'to fly' but WCB /fliay/.

We know of no more than three words in which SG tense /y, u/ also map to WCB /ea/. ${ }^{6}$ These are Blume 'flower', grün 'green', tun 'to do' that are /blumə, gryn, tun/ in SG but /bleam, grean, dean/ in WCB. It is not clear to us why Blume, grün, tun which derive historically from Old and Middle High German $u a$ or $u o$ should have evolved into /ea/ rather than (following the tendency for high vowels to lower before nasals) lowering to /oa/.

\section{$1.2 .4 / \mathbf{e} \varepsilon \mathbf{\varepsilon}: /$}

Both SG and WCB have phonemic oppositions between /e $\varepsilon /$ that are phonetically close to $\mathrm{CV}$ (cardinal vowel) 2 and CV3, respectively, and in which /e/ is longer than $/ \varepsilon /$. The mapping between the two varieties is not systemic, given that BESEN 'broom' has SG/e/ but WCB / $\varepsilon$ / and that MESSER 'knife' has SG/E/ but WCB /e/ (Zehetner 1978, Scheuringer 1990, Stör 1999, Schikowski 2009). Earlier it was noted that WCB /i/ is slightly centralised. If so, it is possible that WCB /e/ is the most peripheral vowel in the WCB front vowel set (Schikowski 2009). Whether WCB /e/ is more peripheral/fronted than SG/e/ is not known.

For historical reasons to do with the divergent way that MHG $\ddot{a}$, $x$ developed in the two varieties (Zehetner 1985, 1989; Scheuringer 1990), some SG unrounded mid vowels are $\mathrm{WCB} / \mathrm{a} /$. This applies predominantly to words with SG $/ \varepsilon: /{ }^{7}$ exemplified by KäSE, but SG $/ \varepsilon /$ can map to WCB /a/ as well as exemplified by MÄNNER.

\subsubsection{WCB open vowels}

WCB has a phonemic opposition between two open vowels /a p/. Phonetically, WCB /a/ is

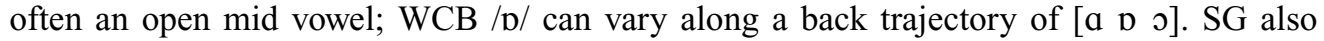
contrasts two open vowels but they are of a phonetically similar central quality and differ principally in length. Thus, SG short /e/ (Lamm 'lamb') vs. SG long /a/ (lahm 'lame'). Many words in SG with short / $\mathrm{e} /$ (SACK) and with long /a/ (GABEL) map to WCB / $/ \mathrm{p}$. By contrast, words with either SG short / $\mathfrak{e} /$ (PFANNE) or SG long /a:/ (KABEL) that typically entered the vocabulary after around the 16 th century map to WCB /a/.

\footnotetext{
${ }^{6}$ This SG $/ \mathrm{y}, \mathrm{u} / \sim \mathrm{WCB} / \mathrm{ea} /$ association is not shown in Figure 3 because as far as we know, this mapping is very specific, occurring only in Blume, grün, tun.

${ }^{7} \mathrm{SG} / \varepsilon: \varepsilon /$ have a similar quality but differ in length. The $\mathrm{SG} / \mathrm{e} \varepsilon: /$ and $/ \varepsilon: \varepsilon /$ contrasts are not very productive. For many SG speakers, /e ع:/ are neutralised as /e/ (Kohler 1995, Bose et al. 2016).
} 


\subsubsection{SG closing diphthongs}

WCB has preserved a distinction from Middle High German between two types of front closing diphthongs whereas SG did not (Zehetner 1985). As a consequence, while STEIN and DREI both map to SG /aI/, they are distinct in WCB as /ai/ and /oa/, respectively (Zehetner 1989, Scheuringer 1990).

$\mathrm{SG} / \mathrm{aI} /$ can also map to WCB /ea/ in STEINE words that are always morphologically related to corresponding words of the STEIN set. Thus, both SG Stein, Steine 'stone, stones' contain the diphthong /aI/ in SG but are distinguished in WCB as $/ \int$ toa/ (with no final $/ \mathrm{n} /$ and according to Kleber 2017, quite possibly a nasalised [oã]) and / $\int$ teana/, respectively. Similarly, klein, kleiner, kleinsten 'small, smaller, smallest' all have /ai/ in SG but /gloa, gleana, gleanstn/ in WCB. The final nasal can no longer be the conditioning environment for this morphological alternation (see remarks on the IHM set in Section 1.2.3 above), because this type of WCB alternation can occur in other contexts, e.g. heiß, heißer 'hot, hotter' that are both produced with /aI/ in SG but as /hoas, heasa/ in WCB. There is further evidence that this alternation is morphologically conditioned. For example, when klein inflects to kleiner due to gender agreement (rather than as above in comparative form) as in ein kleiner Mann 'a small man', WCB has /gloana/ and not /gleana/.

$\mathrm{SG} / \mathrm{y} /$ exemplified by FEUER maps with regularity to WCB /ai/. Consequently, minimal pairs such as Feier, Feuer 'celebration, fire' that are distinguished by /aI, oY/ in SG are homophonous and both map to /ai/ in WCB.

Most SG words with an /av/ nucleus exemplified by HAUS map to /au/ in WCB. On the other hand, there is a context-dependent mapping of SG /av/ to WCB /a/ before labials /p f m/. Thus, SG /au/ in BAUM is WCB /a/ (Kufner 1957, Kleber 2011). Whether this WCB HAUS/BAUM split has been phonologised and lexicalised or whether it is synchronically conditioned is not entirely clear.

\subsubsection{WCB vocalisation of laterals}

The vocalisation of post-vocalic laterals (Kufner 1957, Zehetner 1985, Wiesinger 1990) is a salient characteristic of WCB (Rein 1974, Scheuringer 1990, Vollmann et al. 2015). Typically, the non-high vowel + /1/ sequence in SG (Figure 3: HOLZ, GELD, WALD) is /oi/ in WCB and the SG high vowel $+/ 1 /$ sequence (Figure 3: BRILLE, GEFÜHL, SPIEL, STUHL) maps to WCB /ui/. The main exceptions according to Schikowski, (2009) are in certain loan words (e.g. normal 'normally') and in words often used in religious contexts (e.g. Altar 'altar', Moral 'morality') that are with domain-final /1/ in both varieties.

\subsection{Predicting WCB change}

Because this was a study with children in which the amount of recording time that can be accomplished is restricted (due to e.g. maintaining the child's attention), the empirical part of the study addressed only a small sub-set of the possible systemic and realisational differences between the varieties outlined above. The possibilities for analysing the potential influence of SG on WCB were also constrained by the extent to which it was possible to represent a suitable number of high frequency words that are likely to be known to children pictorially. ${ }^{8}$

Our focus was on six different analyses which were chosen according to three criteria. Firstly, some of the WCB shifts towards SG should be changes within a phonological category that are not perceptually overt and not commented upon, i.e. 'below the level of consciousness' in the sense often intended in social studies of speech (Labov 1994, 2007; Wardhaugh \& Fuller 2015): this applies in particular to the predictions in Sections 1.3.2-1.3.5 below.

\footnotetext{
${ }^{8}$ We also chose not to analyse laterals and their WCB vocalisations which will form part of separate analyses with ultrasound.
} 
Secondly, others should be perceptually more salient, i.e. overt markers of WCB: this is so for prediction in Section 1.3.1 and especially in Section 1.3.6. ${ }^{9}$ Thirdly, some WCB shifts towards SG should be along a trajectory of phonological reorganisation: this is so for all analyses except that in Section 1.3.5. The six analyses and associated predictions based on the idea that WCB is shifting due to the influence of SG were as follows.

\subsubsection{Open vowels}

$\mathrm{WCB} / \mathfrak{p} /$ (GABEL) which is a perceptible marker of WCB should begin to shift towards WCB /a/ (KABEL) since in SG the GABEL/KABEL sets are not contrastive and both map to /a/.

\subsubsection{Long/short vowels}

There should be evidence of a collapse of the WCB contrast between V:C and VC: (see Section 1.2.1 above) given that there is no such contrast in SG (see also Kleber 2017 for some evidence that younger WCB adults are beginning to neutralise this distinction for short/long vowels preceding long/short oral stops).

\subsubsection{Tensity}

If WCB is being influenced by SG, then there should be evidence of the emergence of a tense/lax contrast such that non-low, tense/lax vowel pairs are distinguished by quality, given that such an opposition exists in SG but not in WCB.

\subsubsection{Rounding}

WCB should begin to show evidence of the development of a rounding contrast in front vowels, given that a \pm round opposition exists in non-low front vowels in SG but not in WCB.

\subsubsection{Relative peripherality of /i e/}

In Section 1.2.4 above, it was suggested that $\mathrm{WCB} / \mathrm{i} /$ is more centralised than its $\mathrm{SG}$ counterpart and may be less peripheral than $\mathrm{WCB} / \mathrm{e} /$. If there is an influence of SG on WCB, then $\mathrm{WCB} / \mathrm{i} /$ should front (and/or raise) relative to $\mathrm{WCB} / \mathrm{e} /$, given that in $\mathrm{SG} / \mathrm{i} /$ is typically fronted and raised relative to $\mathrm{SG} / \mathrm{e} /$.

\subsubsection{Diphthongs}

WCB opening diphthongs /ia ua/ exemplified by FLIEGE, FÜSSE might shift in the direction of the corresponding SG monophthongs. In addition, WCB /oa ai/ exemplified by STEIN, DREI might show evidence of a merger, given that they both map to SG /aI/. There might also be a split of WCB DREI, FEUER given that these are both /ai/ in WCB but/aI oY/ in SG.

\footnotetext{
${ }^{9}$ Opening diphthongs are perceptually salient as shown by numerous printed signs e.g. https:// www.merkur.de/bayern/griass-di-affaere-oesterreich-allgaeu-2452017.html with Griaß di (English: 'greetings to you'; the first word in SG is Grüße/grysə/). The /oa/ diphthong is also salient, as shown e.g. by G. Holzheimer's translation into Bavarian of Saint-Exupéry's The Little Prince as Da kloa Prinz (SG: der kleine Prinz); or equally the Bavarian band Hoaß https://www.hoass.de with their slogan: mia san hoaß (English: 'we are hot', SG: wir sind heiß /haIs/).
} 


\section{Method}

\subsection{Participants}

The study for assessing the influence of SG on WCB vowels was based on a combined apparent-time (Weinreich, Labov \& Herzog 1968, Bailey et al. 1991) and longitudinal study in children (Kerswill \& Williams 2000, Trudgill 2008, Nardy, Chevrot \& Barbu 2014, Mooney 2020). For our apparent-time study, comparisons were made between older adults and primary school children. For our longitudinal study, the children were re-recorded 12 and again 24 months after the first recordings had been made when they had just started primary school. Recordings of both adults and children were conducted within the district of Altötting, which is a rural area approximately $90 \mathrm{~km}$ east of the state capital, Munich. The children were from two schools, located $14 \mathrm{~km}$ apart, in the villages of Wald an der Alz and Burgkirchen an der Alz (Figure 1). These schools were selected because, due to their non-urban location, they were likely to include children who were proficient dialect speakers. Generally, inhabitants of WCB rural villages, just like the two where the recordings were made, tend to stay in/return to the area they were born and raised in. Dialect usage is thus predominant and well-respected while SG pronunciation is a marker of an outsider. However, even though most of the teachers spoke WCB dialect, they used SG in class teaching since pupils are supposed to be taught in the standard. Within the recorded classes most of the children were dialect speakers. Nevertheless, the classes were not completely homogeneous and the WCB-speaking children were together with a much smaller number of peers from other regions of Germany (and also from other countries). That is, even if the dialect is certainly present in school life, children are exposed to a greater amount of SG (and regional varieties of SG) as soon as they enter school.

The contact to the children was established via the principals of the schools who granted permission to attend parents' evenings prior to the start of the children's first school year in order to present the study and the experimental set-up.

The adults included 22 WCB speakers (13 female, nine male) who lived in the same villages as the children. One of the adult participants was excluded since she produced the materials in the South-German-coloured standard variety rather than WCB throughout the experiment. The age range of the remaining 21 speakers was 51 to 83 years (mean age of 60.6 years). All speakers were born and raised in the WCB region and had learned dialect from birth. They had no known speech or hearing impairments and wore no hearing aids. Nevertheless, some age-related hearing decline cannot be ruled out (especially among the oldest of the participants aged 73,77 , and 83 years).

The children included 21 (12 female, nine male) WCB speakers and were recorded in their first year of attendance at primary school (average age 6.5 years). Parental questionnaires were used to ensure that both parents were WCB speakers and that the children had learned and spoke dialect from birth. The same children were re-recorded one and two year(s) later (i.e. at age 7-8 and 8-9 years). Two of the children moved away in the first school year and another two in the second school year. Hence 19 WCB-speaking children (12 female, seven male) remained for the second-year recording and 17 (11 female, six male) for the third-year recording. The data from one of the children with speech and hearing difficulties who had participated in the recordings from all three time points were not included in the analysis. The final count of analysed children was therefore 20 (year 1), 18 (year 2) and 16 (year 3).

\subsection{Experimental set-up}

The design of the study involved productions of the same words for all participants of both age groups using a picture naming task. The picture naming task was used without any orthography. This method was chosen to obtain dialectal, semi-spontaneous data while 


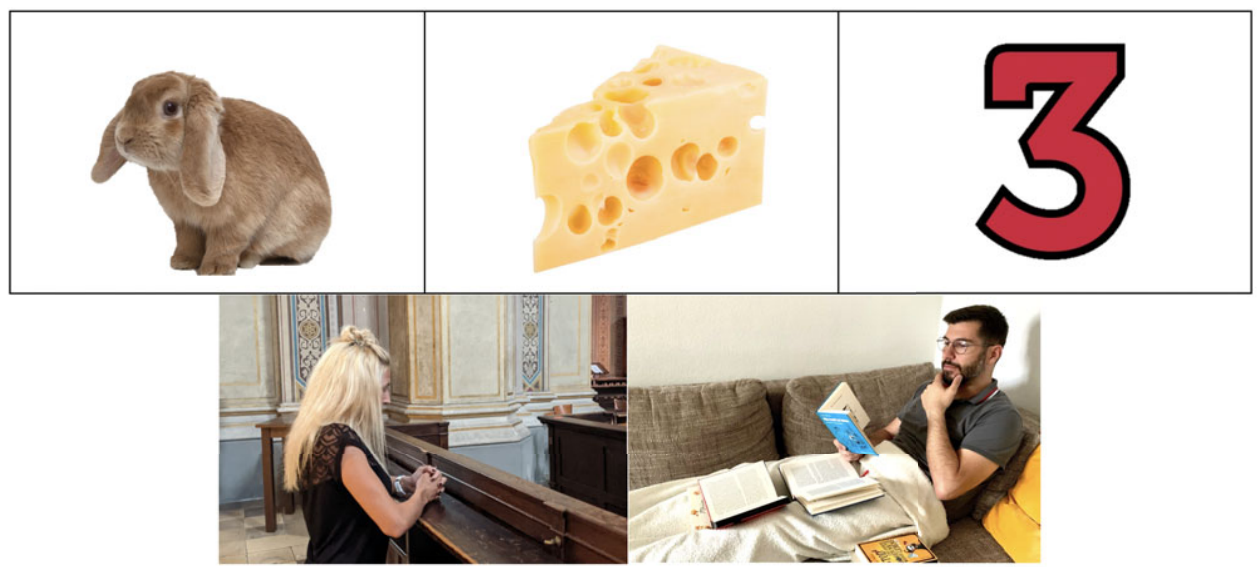

Figure 4 Sample pictures used in the study. The items are: Hase /hps/ 'rabbit' (top left), Käse /kas/ 'cheese' (top mid), drei /drai/ 'three' (top right), beten /betn/ 'to pray' (bottom left), and lesen /lesn/ 'to read' (bottom right).

constraining the degree of spontaneity. Picture-naming and word repetition tasks have been found to be useful methods for eliciting single words and for controlling the context (Edwards $\&$ Beckman 2008). There was no priming with the respective target words and vowels, neither orthographically nor verbally. Only in the cases where the target words were verbs (e.g. lesen 'to read' and beten 'to pray') did the experimenter ask: 'What does the woman/the man do?' before the production to elicit a verb instead of a noun.

All words were presented as real pictures, predominantly on plain white background, as exemplified in Figure 4. Exceptions to this pattern were e.g. lesen 'to read' and beten 'to pray' (see also Figure 4).

Adult participants were tested in a quiet room in their homes and produced each word from a picture that was presented on a monitor. The children were tested individually in a quiet room in their respective schools. For the children, the production experiment was constructed as a game in which a human comic figure travelled through space (first year of recordings) or over a treasure map (second and third year of recordings). The game began with a picture of a figure at some starting point on the background of space or a treasure map that moved across several landmarks (planets in the space setting or small circles in the treasure map setting). After approximately every 15 th item, a picture with the figure on the respective background appeared again having advanced by one step (accompanied with some gaming sound effects), until the 'goal' at the end of the experiment had been reached. This was done in order to ensure that the children maintained interest and motivation throughout the whole experiment.

The recordings were made with an audio interface (M-Audio Fast Track) and a condenser headset microphone (Beyerdynamic TG H54) and digitised at $44.1 \mathrm{kHz}$, using the SpeechRecorder software version 3.12.0. (Draxler \& Jänsch 2004). The pictures were displayed one at a time on a computer monitor. The participants were seated in front of the screen of a MacBook Pro (2016, 13 inch). The adults were instructed to produce the pictures in their dialect. In order to encourage the children to speak WCB naturally, the children interacted with the experimenter (the first author, who is a WCB speaker from the same area) for some time before and during the picture naming task. There was no time pressure in producing the words which were advanced manually by the experimenter when the participant was ready. The total time to participate in the experiment was approximately 20 and 30 minutes for adults and for children, respectively. 


\subsection{Materials}

The 58 pictures were based on frequently occurring words (predominantly nouns) that are easy to visualise. They were also designed both in order to represent acoustically the WCB monophthong and diphthong spaces (Figure 2) and for analysing the types of questions presented in Section 1.3 above. The picturable words which are listed in Appendix B were either monosyllabic (26/58 words) or disyllabic (32/58 words) with trochaic stress (i.e. the first syllable had primary lexical stress followed by a lexically unstressed syllable). The wordlist included as far as possible words whose (target) vowels differ considerably between WCB and SG, so that the distinction between dialect or standard productions was clear and easily identifiable by native speakers.

The target vowels were in all cases in the initial syllable with primary lexical stress and included one of seven WCB monophthongs / $\mathrm{p}$ a i u o e $\varepsilon$ / or five diphthongs /oi ai oa ia ua/ in a wide range of segmental contexts. Since the words were produced in isolation or at least most prominent when embedded in a phrase, the initial syllable was also nuclear accented. The words were presented in randomised order and repeated four times (resulting in 232 tokens per participant). The randomisation was generated automatically and therefore varied each time the experiment was run which led to a different order between speakers and also within the same speaker in the repeated recordings.

A number of productions were completely excluded from further consideration in the present study. There were four reasons for doing so:

1. Some word types were completely excluded from further analysis because the children had so often produced a completely different word than the intended target item. This was so for Heu 'hay' (produced as Stroh 'straw') and Licht 'light' (produced as Lampe 'lamp').

2. Kirche 'church', Schnur 'string', and Uhr 'clock' were also completely excluded since these are opening diphthongs that are derived diachronically or synchronically from a post-vocalic $/ \mathrm{r} /$ and are not the subject of the present investigation (see Section 1.2 and footnote 2 above).

3. Some words were completely excluded because they were produced in SG much more often than WCB. These were Besen 'broom', beten 'to pray', Ei 'egg', Futter 'fodder', Hütte 'cabin', Müll 'waste', Reh 'deer', Säge 'saw', Schnee 'snow', Schlüssel 'key', Schüler 'pupil'.

4. All other words and word types were retained but occasionally some tokens were removed because they were produced in SG and not in WCB.

The exclusion of words in $(3,4)$ was based on auditory criteria. In almost all cases, SG instead of WCB productions were very clearly perceptible either in the target vowel (e.g. the production of SG /ar/ instead of WCB /oa/ for $E i$ ' $\mathrm{egg}$ ') or in other consonants and vowels of the target word (e.g. SG $/ \mathrm{kabl} / \mathrm{vs}$. WCB / kabe/ for Kabel 'wire'). The proportion of adult productions removed as a consequence of $(3,4)$ together was $14.1 \%$; for children, the proportion of words removed due to $(3,4)$ together was $39.9 \%, 38.5 \%, 38.0 \%$ for years $1-3$, respectively.

The final count of word repetitions retained for analysis is shown in Appendix B.

\subsection{Data preparation and analysis}

The recordings were manually segmented in order to identify the target words, given that the children tended to produce considerably more speech than just the targeted item. Target words were then automatically segmented and annotated with the Munich Automatic Segmentation System (Kisler, Reichel \& Schiel 2017). All subsequent analyses were carried out using the $E m u D B$ system and emuR package in R (Winkelmann, Harrington \& Jänsch 2017). Formants were calculated using the LPC algorithm in Praat (Boersma \& Weenink 1992-2016) with the 
Burg algorithm. The analysis window had a length of $0.025 \mathrm{~s}$ and the ceiling of the formant search range was set to $7000 \mathrm{~Hz}$ for children, $5500 \mathrm{~Hz}$ for adult females, and $5000 \mathrm{~Hz}$ for adult males. Pre-emphasis was applied with a slope of $+6 \mathrm{~dB} /$ octave for frequencies above $50 \mathrm{~Hz}$.

Vowel segment boundaries and formant errors were manually corrected. The correction of formants was especially necessary for the child speech data in which e.g. a formant had been mis-tracked as a higher or lower formant number. The acoustic vowel onset and offset were typically defined as the onset/offset of periodicity and/or for the interval over which a formant structure was clearly visible. F1 and F2 of each vowel were linearly time-normalised between the acoustic on- and offset to eleven data points and then smoothed to remove microperturbations using a five-point median filter.

All data were speaker-normalised by converting formant frequencies into $z$-scores (Lobanov 1971) in order to reduce the influences of anatomical differences in size and shape of the different speakers' vocal tracts. This was done with (1):

(1) $F_{i, j, k(t)}^{*}=\left[F_{i, j, k(t)}-\right.$ mean $\left.F_{i, j}\right] / \mathrm{sd} F_{i, j}$

in which $F_{i, j, k(t)}^{*}$ and $F_{i, j, k(t)}$ are, respectively, the normalised and raw formant frequency values of formant number $j(j=1,2,3)$ produced by speaker $i$ in utterance $k$ at timepoint $t$ and where mean $F_{i, j}$ and sd $F_{i, j}$ are the mean and standard deviation of all formant values between the acoustic onset and offset for formant number $j$ with respect to that speaker's $/ \mathrm{a} /$, /o/, and /e/ vowels. These were chosen, because they mark the WCB corner vowels i.e. those with the most extreme F1 and F2 values. Durations for target vowels and their subsequent consonants were measured and normalised relative to the duration of the word in which they occurred.

The formant trajectories between the vowel's acoustic onset and offset of the first and the second formant were each decomposed into a set of $1 / 2$ cycle cosine waves using discrete cosine transformation (DCT; see Harrington \& Schiel 2017 for formulas and details). For the present study, the first three DCT coefficients, $k_{0}, k_{1}, k_{2}$, were calculated; they are proportional to the mean, linear slope, and curvature of the trajectory, respectively.

The DCT models the shape of a trajectory but does not represent duration.

The (logarithmic) distance $d$ of a vowel $\vec{x}_{i}$ in a three or six-dimensional space of DCT coefficients to another vowel category $\vec{c}$ was also calculated separately by speaker and is given (2):

(2) $d\left(\vec{x}_{i}\right)=\log \left(\sqrt{\left\|\vec{x}_{i}-\vec{c}\right\|^{2}}\right)$

(In (2), $\|$ denotes vector magnitude and $\vec{c}$ is the centroid of the vowel category to which the inter-Euclidean distances were calculated.) The formula in (2) was used in Section 3.4, for example, to calculate the distance of a speaker's F2 trajectory in the vowel of Messer 'knife' to the mean F2 trajectory to the same speaker's lesen 'to read' and vice versa. The formula in (3), which is the one-dimensional form of (2), was used in Section 3.6:

(3) $d\left(x_{i}\right)=x_{i}-c$

In Section 3.6, $x_{i}$ was the DCT coefficient $k_{0}$ calculated for the F2 trajectory of any /e/ vowel and $c$ was the mean of all the $k_{0}$ values calculated across the same speaker's $/ \mathrm{i} /$. Since $k_{0}$ is proportional to the trajectory mean, (3) was used to measure the distance between the F2 trajectory mean for any given /e/ vowel and the trajectory mean averaged across /i/ vowels produced by the same speaker.

Statistical tests were carried out with a linear mixed effect regression model using the LMER function from the lmerTest package in $\mathrm{R}$ (Kuznetsova, Brockhoff \& Christensen 2017). For the analyses in Sections 3.2, 3.3 and 3.5, the model was of the form (R notation) in (4):

(4) dependent $\sim$ group + year $+(1 \mid$ speaker $)+($ group $\mid$ word $))$ 
In (4), dependent was the dependent variable, group a two-level fixed factor child vs. adult, year a four-level fixed factor for adults and children recorded in the first, second, and third years, speaker a random factor for the participant, and word a random factor for the word. The analysis in Section 3.4 extended (4) to include the vowel, $V$, as a fixed factor, as in (5):

(5) dependent $\sim$ group + year $+V+$ group: $V+$ year: $V+($ V|speaker $)+($ group $\mid$ word $))$

When year was significant in (4) or (5) (which means that adults and children recorded in their first three years potentially all differed from each other), the results of post-hoc $t$-tests were computed using the R package emmeans (Lenth 2019).

\section{Results}

We begin with some general comments about the WCB vowel and diphthong space (Section 3.1). We then assess whether WCB is being influenced by SG with respect to the six issues outlined in Section 1.3 and discussed in Sections 3.2-3.7 below. The main indicator of change will be evidence of whether the children's vowels were shifted towards SG compared with those of adults. Another indicator is whether such adult-child differences were more marked for children in their second year and even more in their third year of recording (henceforth year 2 and year 3) compared with the same children in their first year of recording (year 1). In general, speech tempo is unlikely to be a confounding influence, since word and vowel durations (for the data points shown in Figure 5 below) are quite comparable. These were 488/499/502/490 ms (word duration) and 157/158/160/160 ms (vowel duration) for adults/year 1 children/year 2 children/year 3 children, respectively.

\subsection{Overview}

The plot of monophthongs extracted at the temporal midpoint in the F1 $\times$ F2 space in Figure 5 (and their aggregates in Figure 6) shows clear evidence of three front vowels $/ \mathrm{i}$ e $\varepsilon /$, three back vowels / $\mathrm{u}$ o $\mathrm{p} /$ and an open vowel /a/. Consistently with some observations, /e/ is indeed more peripheral than /i/ at least based on F2. Based on the acoustic evidence and auditory impressions, $/ \mathrm{p} /$ is slightly more open than [o]. $/ \mathrm{o} /$ is the most peripheral back vowel. $/ \mathrm{u} /$ is more central than CV8 and possibly closer to [U]. There are unequivocally three level/closing diphthongs and three opening diphthongs (N.B.: /ea au/ were not analysed and hence not included in Figure 6). The main divergence in quality for the diphthongs from the symbols used for the broad phonemic transcription are as follows: the second component of/ai/ is midfront, thus [ae]; the second component of /ui oi/ is central of CV1 (and the first component of /ui/ is central of CV8), thus [UI OI], respectively, the second components of the falling diphthongs of /ia ua/ are phonetically mid-central (and their first components central of CV1, CV8, respectively), thus [Iə Uə].

There are generally quite close correspondences in Figures 5 and 6 between the adults and the children, but also some visible differences. Two of these differences are analysed further in Sections 3.2 and 3.6: these are (i) that $/ \mathrm{p} /$ is further from /o/ for children and (ii) that the difference along the F2 axis between /e/ and /i/ is greater for adults. In addition, Figures 5 and 6 suggest - for adults compared with children - (i) a smaller separation between /e $\varepsilon /$, (ii) a smaller distance of $/ \mathrm{u}, \mathrm{p} /$ as well as the first components of /ui oa/ from /o/, and (iii) a more open $/ \mathrm{a} / \mathrm{(} / \mathrm{a} /$ is further from the first component of /ai/ and from the second component of $/ \mathrm{oa} /$ in adults). 


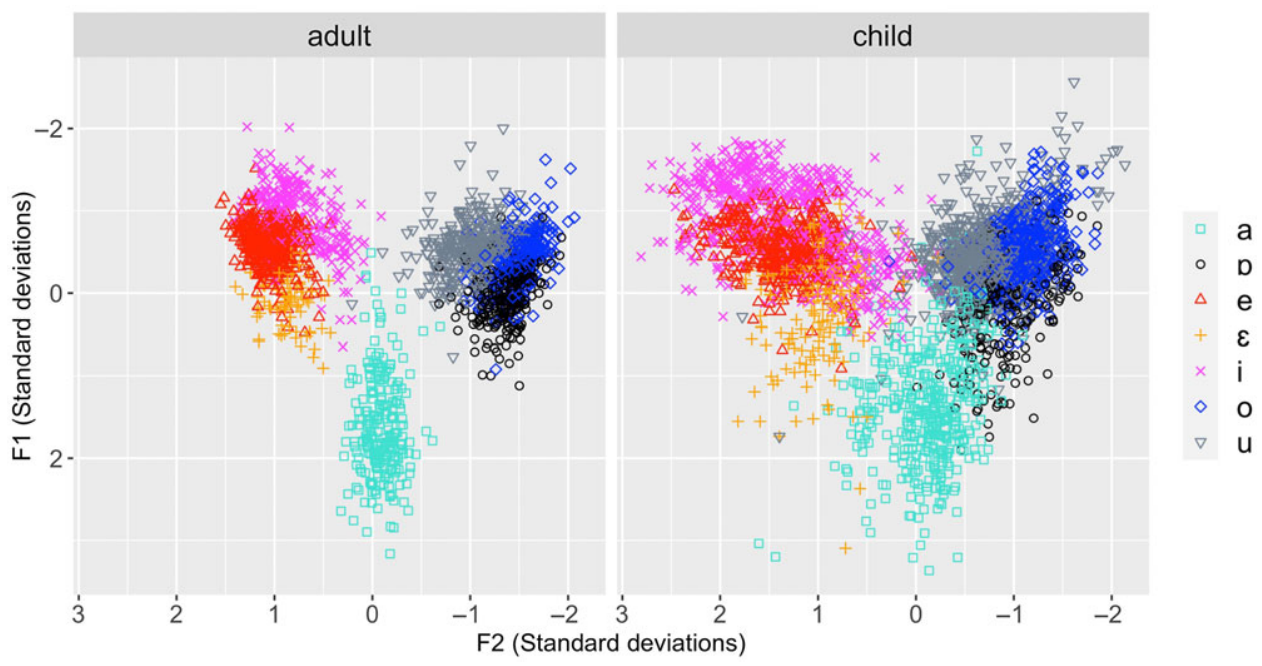

Figure $\mathbf{5}$ The first two formants extracted at the temporal midpoint in monophthongs for adults and children.

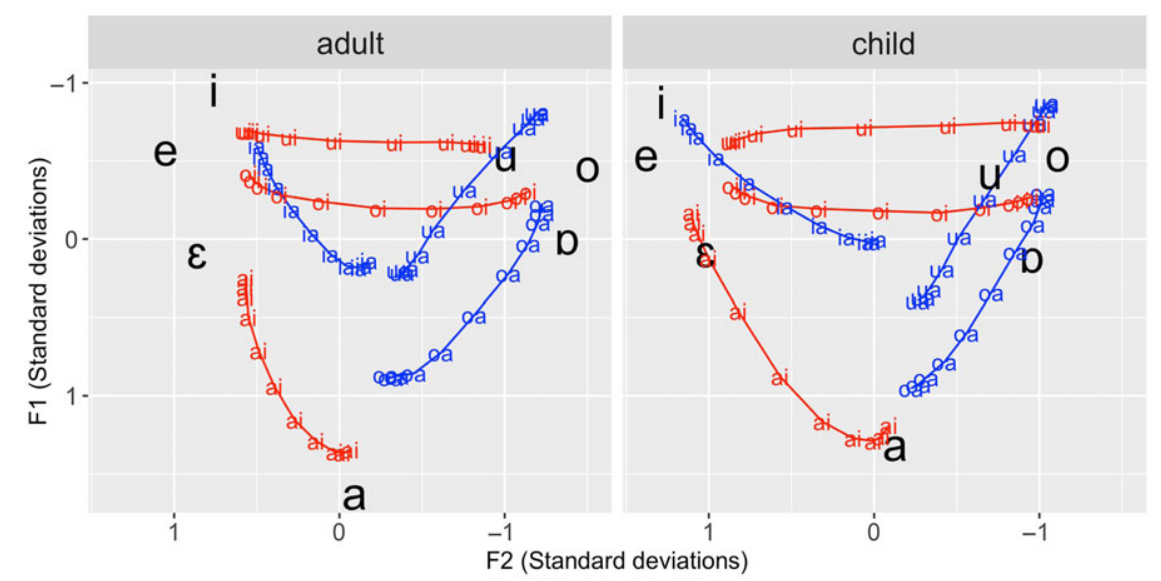

Figure 6 Aggregated level/closing (red) and opening (blue) diphthong trajectories in the F1 $\times$ F2 plane superimposed on the mean positions (black) of the monophthongs in adults and children.

\subsection{Open vowels}

The difference between the positions of $/ \mathrm{p} /$ and $/ \mathrm{a} /$ in the respective groups was assessed by calculating the inter-Euclidean distances in a six-dimensional F1 $\times$ F2-DCT space between all $/ \mathrm{a} /$-vowels to the combined centroid of $/ \mathrm{p} /$-vowels and vice versa separately by speaker following equation (2) (Section 2.4). The calculation was based on all /a, $\mathrm{p} /$ words shown in black in Appendix B. These included three /a/ words (Kabel 'wire', Käse 'cheese', Klasse 'class') and four/p/words (Gabel 'fork', Glas 'glass', Hase 'rabbit', Sack 'sack'). The results (Figure 7) show greater inter-Euclidean distances for adults than for year 1, year 2 and year 3 children. This finding is consistent with the evidence in Figure 5 which shows that $/ \mathfrak{p} /$ is closer to $/ \mathrm{a} /$ in children than in adults. The results of the mixed model in (4) with the Euclidean distances as the dependent variable showed a significantly higher inter-Euclidean distance (i.e. $/ \mathfrak{p} /$ positioned further from $/ \mathrm{a} /)$ for adults compared with year $2\left(t_{40.1}=3.2, p<.05\right)$ and year $3\left(t_{40.9}=4.0, p<.01\right)$ children, as well as significant differences between year 1 and year 2 children $\left(t_{1097.2}=4.7, p<.001\right)$, year 2 and year 3 children $\left(t_{1091.5}=3.1, p<.05\right)$ and year 


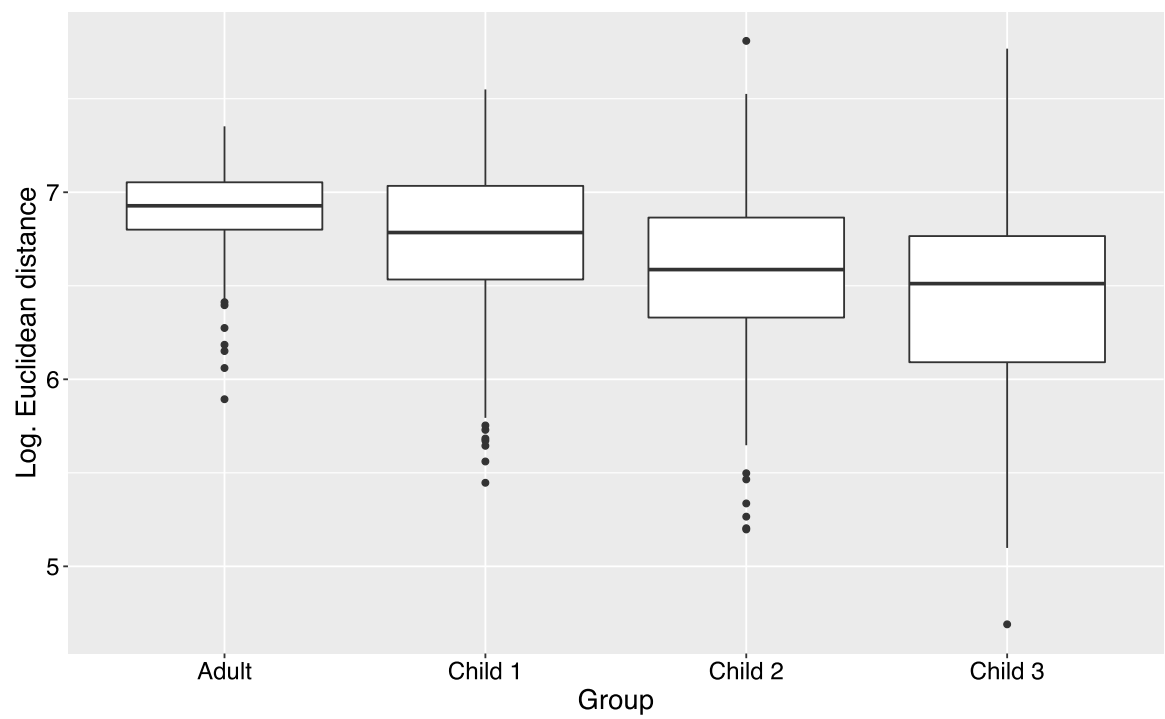

Figure 7 Logarithmic inter-Euclidean distance calculated in a six-dimensional F1 x F2 DCT-space between /D/ and /a/ for adults and three groups of children recorded in their first (Child 1), second (Child 2) and third (Child 3) year of school attendance.

1 and year 3 children $\left(t_{1103.5}=7.3, p<.001\right)$ in the same direction. Even if the difference between adults and children from year 1 was not significant, the results combined with the evidence in Figure 7 suggest a trend of a decreasing difference between $/ \mathrm{p} /$ and $/ \mathrm{a} /$ from adults to year 1 to year 2 to year 3 children. Nevertheless, this result (as with all of those in this study) may well not be representative of the population of WCB children, given the small number of children that produced these words in year 2 (between eight and nine) and in year 3 (between five and seven).

\subsection{Long/short vowels}

The purpose was to determine whether there was any evidence for a long vs. short vowel distinction that is phonetically conditioned by a following short vs. long consonant, and to assess whether any such relationship is differently manifested in adults than in children. We began by examining vowels for which there were short vs. long pairs of the same quality before $/ \mathrm{s} /$. There were four such words in the database. These included Käse and lesen that have a long vowel followed by a short voiceless consonant, thus [ $\left.\mathrm{k}^{\mathrm{h}} \mathrm{a}: \mathrm{s}\right]$, [leisn] and Klasse and Messer for which the vowel is short and the consonant long and voiceless thus [klas:], [mes:e]. As shown in Figure 8, older speakers showed a clear separation between V:C and VC: based on quantity. In $\mathrm{V}: \mathrm{C}$, the vowel was long and /s/ short and vice versa for VC:. Figure 8 shows that vowel duration separated $\mathrm{V}: \mathrm{C}$ and $\mathrm{VC}:$ in children. Figure 8 also shows that the overlap between $\mathrm{V}: \mathrm{C}$ and $\mathrm{VC}$ : on consonant duration was, by contrast, greater for children than for adults. Based on the results from Figure 8, we tested whether there was a reduction in post-vocalic consonant duration in children when the preceding vowel is short. There were 11 available words in our database with phonetically short vowels. These were beten 'to pray', Butter 'butter', Hütte 'cabin', Klasse 'class', Löffel 'spoon', Messer 'knife', Rutsche 'slide', Schlüssel 'key', Schnecke 'snail', Spinne 'spider', Suppe 'soup'. However, we excluded from further consideration beten 'to pray', Hütte 'cabin', and Schlüssel 'key' because they were produced too infrequently (as explained in Section 2.3 and shown in Appendix B).

For the remainder, we measured the post-vocalic consonant duration from the acoustic onset to the acoustic offset of aperiodicity following the vowel in plosives and fricatives and between the acoustic onset and offset of /n/ in Spinne 'spider'. Figure 9 suggests a trend 

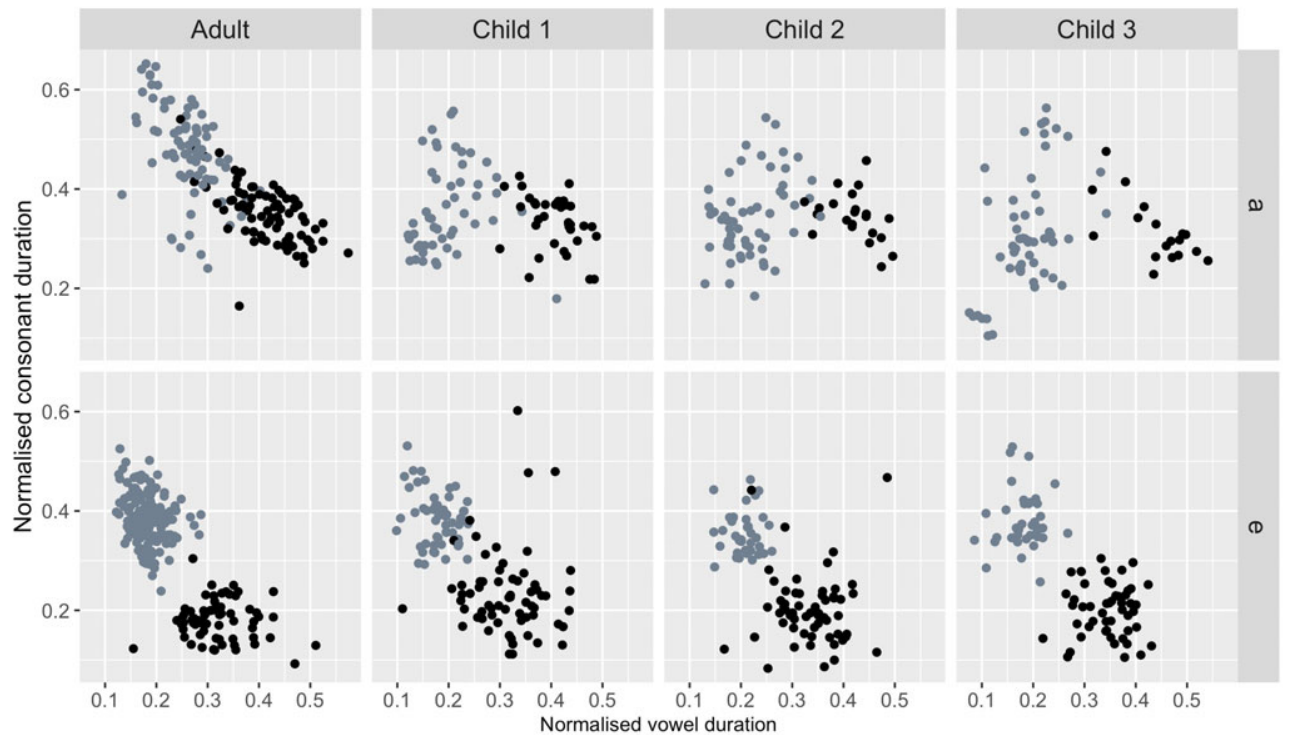

Figure 8 Durations of the vowels /e/ and /a/ and the fricative /s/ as a proportion of word duration in phonetically short (grey) and long (black) vowels in two /a/ words (top) and two /e/ words (below) for adults, year 1, year 2 and year 3 children.

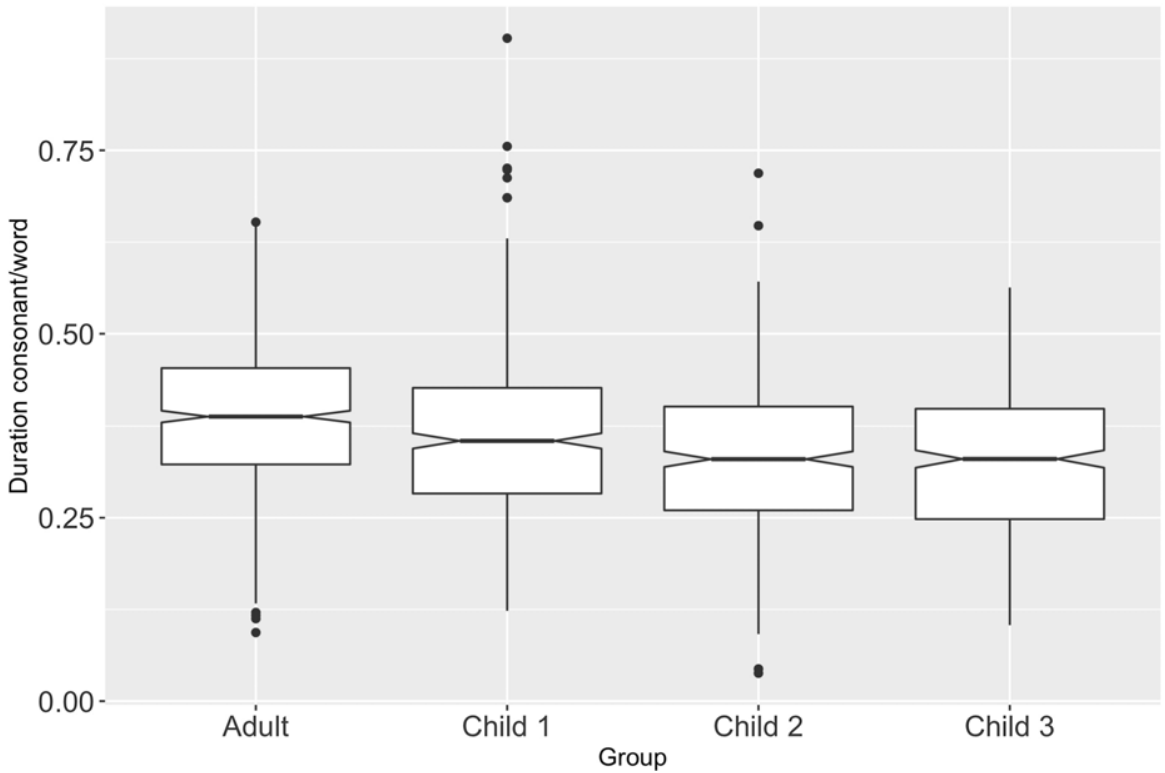

Figure 9 Durations of the coda consonant normalised for word duration in several words that all have a preceding phonetically short vowel for adults and the children recorded in the first, second and third years.

in which the post-vocalic consonant duration decreased from adults to children recorded in the first and then in their second year. In their third year, the duration seems to be at about the same level as for year 2. The results of applying a linear mixed model as in equation (4) (Section 2.4) with the ratio of the consonant to word duration as the dependent variable showed no significant differences between adults and children in their first year, a significant difference between adults and children recorded in their second $\left(t_{12.3}=3.1, p<.05\right)$ and in 
their third year $\left(t_{12.4}=3.4, p<.05\right)$, and a significant difference between children recorded in their first and second year $\left(t_{1941.2}=6.2, p<.001\right)$ as well as between children recorded in their first and third year $\left(t_{1945.0}=7.0, p<.001\right)$. Consistently with Figure 9 , the difference between the children in their second and third year was not significant. However, these results, together with the evidence in Figure 9, suggest a trend in WCB in which there was a decrease in the duration of the post-vocalic consonant after short vowels at least from adults to year 1 to year 2 children, while year 3 children range at a similar (low) level as for year 2.

\subsection{Tensity}

The focus in this section is on whether children are beginning to show evidence of an SG tense/lax contrast that does not exist in WCB. For this purpose, we compared words that have the same quality in WCB but which are tense and lax in SG. These included Dieb 'thief', Wiese 'lawn', Spinne 'spider', Tisch 'table', which are all /i/ in WCB but which are tense /i/ (Dieb, Wiese) vs. lax /I/ (Spinne, Tisch) in SG. They also included lesen 'to read', Messer 'knife' and Bett 'bed', which are all /e/ in WCB but tense /e/ (lesen) and lax /E/ (Messer, Bett) in SG. Finally, Rose 'rose', Hose 'trousers', Rock 'skirt', Stock 'stick' were also included; they are all /o/ in WCB but tense /o/ (Rose, Hose) and lax (Rock, Stock) /o/ in SG. No other sets of words in the database with sufficient numbers of speakers/repetitions that fulfilled these criteria (of the same quality in WCB but tense/lax in SG) were available.

In Standard German, F2 is typically higher in tense /i/ (Dieb, Wiese) than in lax /I/ (Spinne, Tisch) and higher in tense /e/ (lesen) vs. lax /E/ (Messer, Bett) while F1 is typically higher in tense /o/ (Rose, Hose) than in lax /o/ (Rock, Stock). Such formant differences should be observable in WCB children, if children are being influenced by SG. There is some evidence from Figure 10 that the F2 separation between such tense/lax pairs is greater for children than for adults in the front vowels /i e/ but not for F1 in Rose/Hose vs. Rock/Stock. There seems to be no evidence of any longitudinal trend, i.e. the degree of separation between SG tense/lax pairs was about the same for data from the 1st, 2nd and 3rd year of child recordings.

In order to quantify these observations further, the inter-Euclidean distances between vowels corresponding to SG tense/lax pairs were calculated separately for $/ \mathrm{i}$ e o/ and separately by speaker from equation (2) (Section 2.4). For /i/, (2) was applied twice: firstly, the Euclidean distances in a three-dimensional F2-DCT were calculated of all Spinne/Tisch vowels to the (combined) vowel centroid of Dieb/Wiese and, secondly, in the other direction of all Dieb/Wiese vowels to the centroid of Spinne/Tisch. Exactly the same procedure was applied to /e/ (lesen vs. Messer/Bett) and to /o/ (Rose/Hose vs. Rock/Stock) with the exception that the calculation was made in an F1-DCT space for /o/. Figure 11 shows that these inter-Euclidean distances were greater for children than for adults, although only marginally so for $/ \mathrm{o} /$. The results of applying a mixed model as in equation (5) showed significantly greater inter-Euclidean distances between adults and children in $/ \mathrm{i} /\left(t_{17.7}=9.1, p<.001\right)$ and in $/ \mathrm{e} /\left(t_{21.3}=3.6, p<.01\right)$ but not in /o/. Furthermore, there were no increases in the interEuclidean distance between children in their first, second and third year. There is therefore no evidence of a trend for vowels corresponding to tense/lax differences in SG to become more distant from each other longitudinally.

\subsection{Rounding}

The test for the development of rounding was applied to /e/ in Bett 'bed', lesen 'to read', Messer 'knife', where it is unrounded / $\varepsilon$ e $\varepsilon /$, respectively, in the standard (the $-\mathrm{R}$ group) as well as to /e/ in Löffel 'spoon', Vögel 'birds', where it is rounded /œ ø/, respectively, in the standard (the $+\mathrm{R}$ group). There were insufficient numbers of words like Hütte 'cabin' and Schlüssel 'key' (WCB /i/; standard: /Y/) for a comparable analysis to be carried out for high vowels.

Lip-rounding lengthens the vocal tract and causes a lowering of formant frequencies and especially F2 in the case of (mid) front vowels (Lindblom \& Sundberg 1971 see also Figure 2 

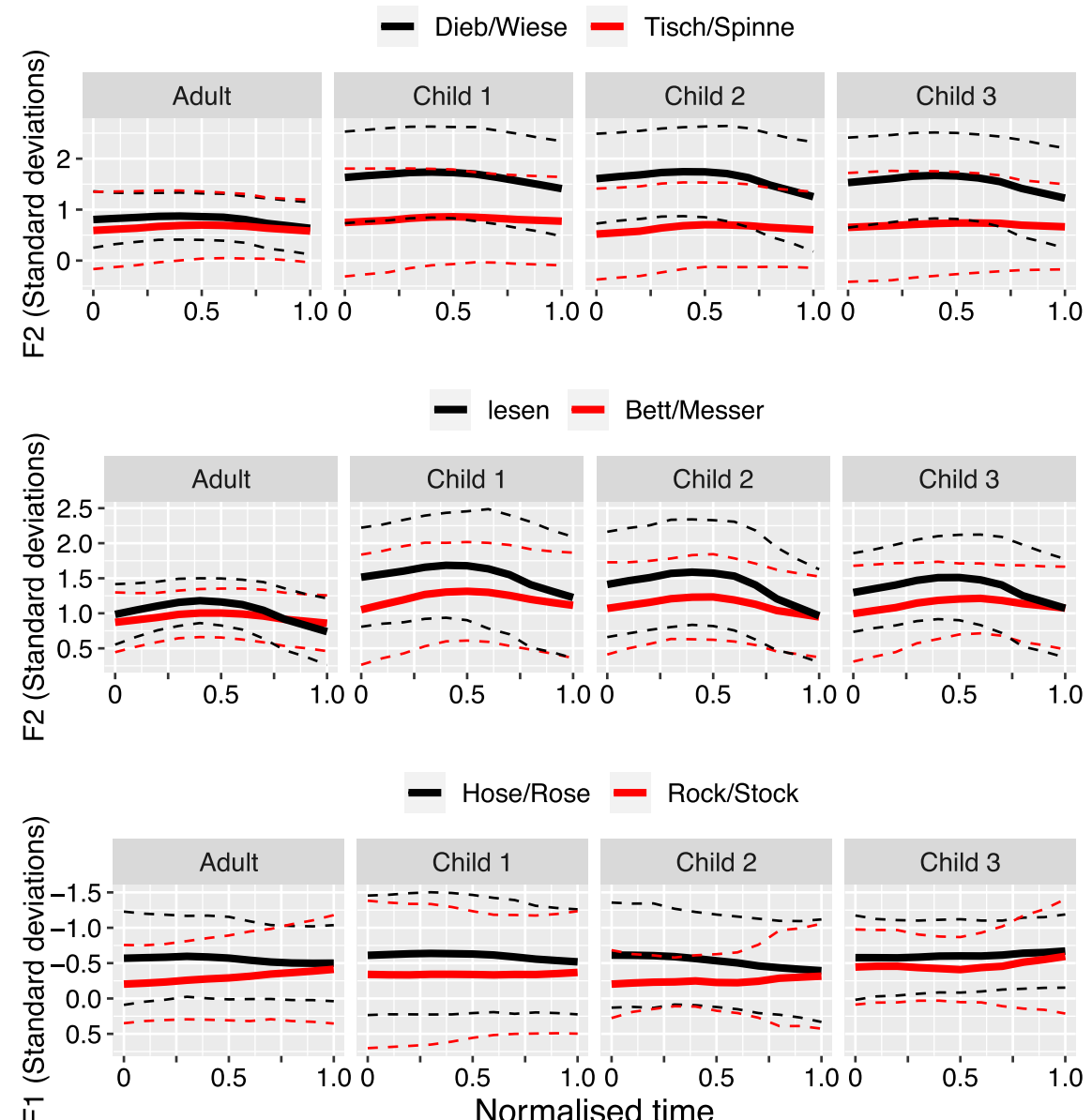

- Hose/Rose Rock/Stock
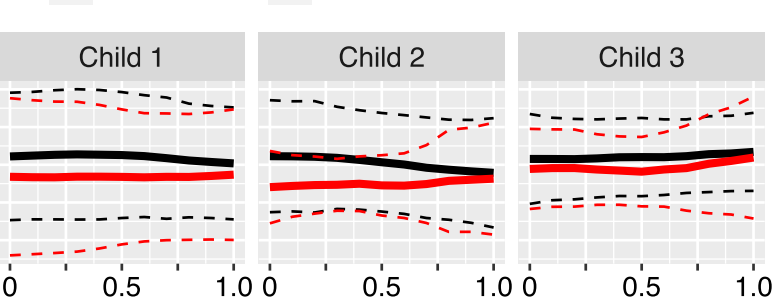

Normalised time

Figure 10 F2 trajectories for /i/ (top) and /e/ (middle) and F1 trajectories for /o/ (bottom) aggregated by word and speaker group (adults; year 1, year 2 and year 3 children). Black/red correspond to tense/lax in Standard German. Solid/dashed lines: trajectories of the mean and at 1.96 standard deviations from the mean, respectively.
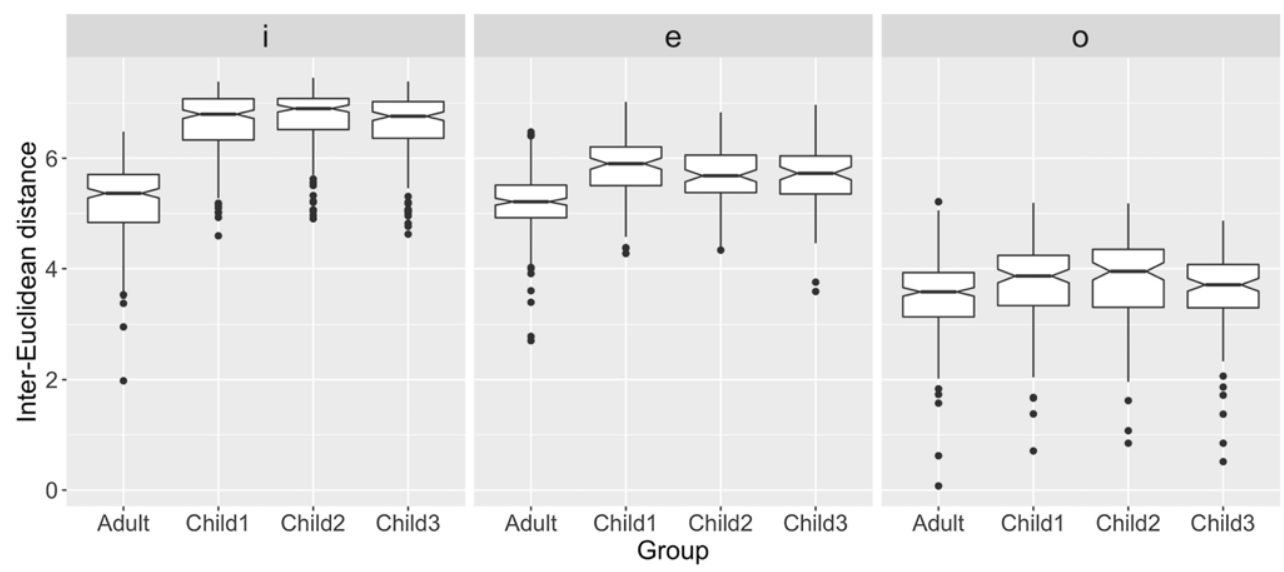

Figure 11 Logarithmic inter-Euclidean distance between vowels that are tense and lax in Standard German for adult speakers and three groups of children recorded in their first (Child 1), second (Child 2) and third (Child 3) years shown separately for /i e o/. 


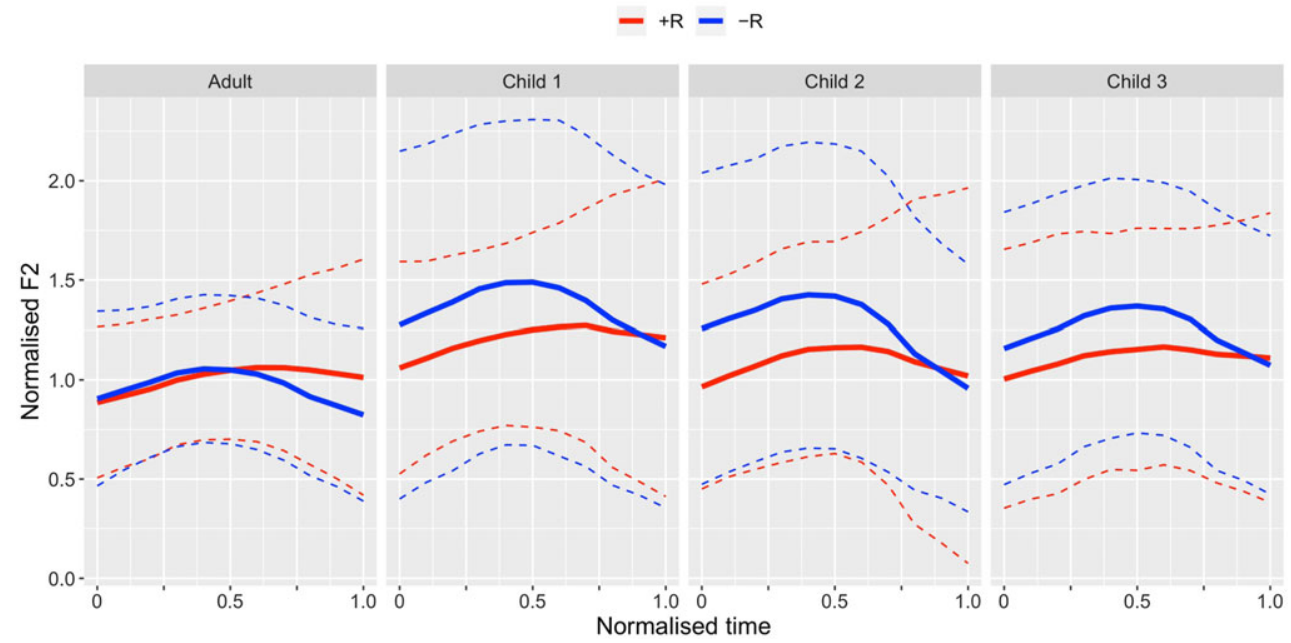

Figure 12 Time-normalised F2 trajectories of WCB /e/ aggregated by whether they are unrounded $(-R)$ or rounded $(+R)$ in the standard and separately for adults, year 1, year 2 and year 3 children. Solid/dashed lines: trajectories of the mean and at 1.96 standard deviations from the mean, respectively.

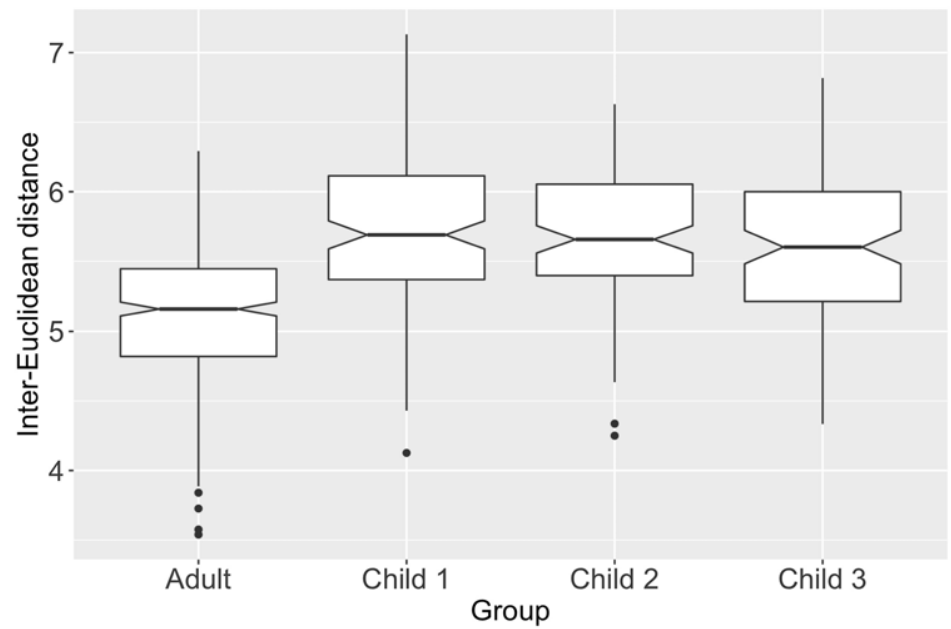

Figure 13 Logarithmic inter-Euclidean distance between WCB /e/ vowels that are rounded and unrounded in Standard German for adult speakers and three groups of children recorded in their first (Child 1), second (Child 2) and third (Child 3) years.

in Vaissiére 2009). Figure 12 shows that there were only minor F2 differences between the $\pm \mathrm{R}$ groups for adults. But in children, $\mathrm{F} 2$ of $-\mathrm{R}$ vowels was higher than for $+\mathrm{R}$ vowels.

We further quantified these differences by calculating the inter-Euclidean distances from $-\mathrm{R}$ vowels to the $+\mathrm{R}$ centroid and from $+\mathrm{R}$ vowels to the $-\mathrm{R}$ centroid in an F2-DCT space using (2) and as always separately by speaker. The results of these calculations in Figure 13 show a greater inter-Euclidean distance between $\pm \mathrm{R}$ groups for children compared to adults.

The results of applying a mixed model as in equation (4) (Section 2.4) showed significantly greater inter-Euclidean distances between adults and children $\left(t_{24.8}=6.4, p<.001\right)$ and, compatibly with Figures 12 and 13, no differences between children in their first, their second and their third year of recordings. 


\subsection{Relative positions of /i el}

The test was whether /e/ is fronted relative to /i/ in adults and whether this relationship is being reversed in children. The words available for this investigation were those in the /e i/ sets in Appendix B. However, in order to avoid possible confounds, we removed from further consideration those words that we had found to be influenced due to tensity (Section 3.3) and rounding (Section 3.4) differences in the standard. The only remaining words were /e/ in lesen 'to read' and /i/ in Dieb 'thief', Wiese 'lawn'.

The F2 trajectories in Figure 14 show that F2 of /e/ is lower in adults than in children. They also suggest a trend in which there is a progressive increase in F2 of /i/ relative to F2 of /e/ from adults to children in their first and then in their second and third year. The trend is, however, less apparent in the F2 difference between /i/ and /e/ in Figure 15 calculated with equation (3). Quite the contrary, there even seems to be a trend of decreasing F2 differences from year 1 to year 2 to year 3 within the children.

A statistical test using the equation in (4) with the dependent variable shown in Figure 15 showed significant differences between adults and children for all of the recording timepoints

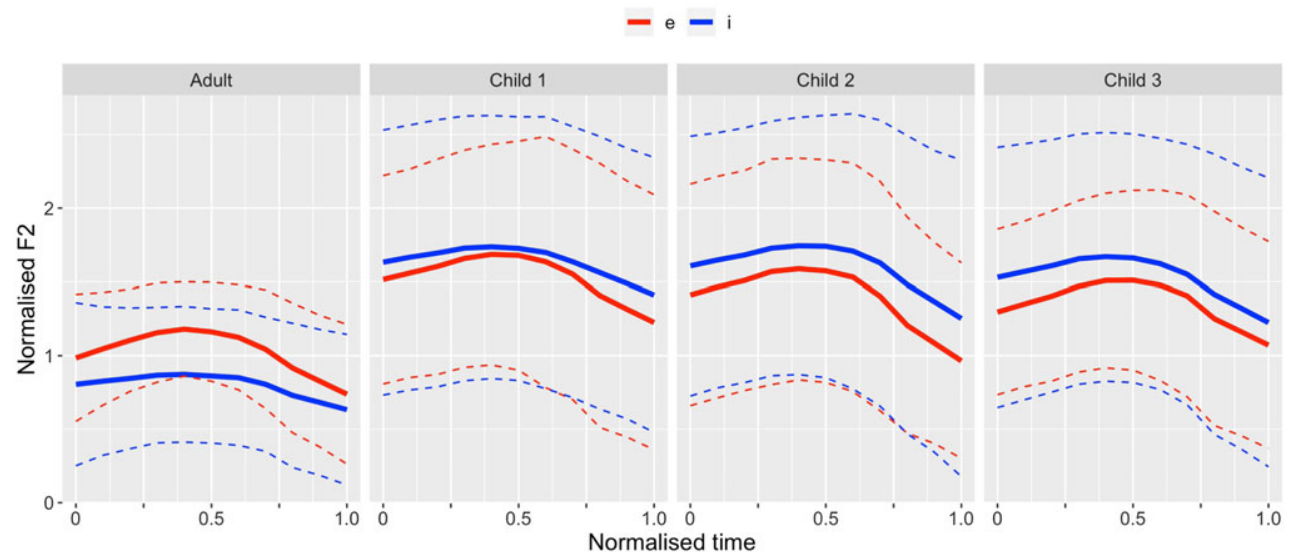

Figure 14 Time-normalised F2 trajectories of /e i/ vowels aggregated separately for adults, year 1, year 2 and year 3 children. Solid/dashed lines: trajectories of the mean and at 1.96 standard deviations from the mean, respectively.

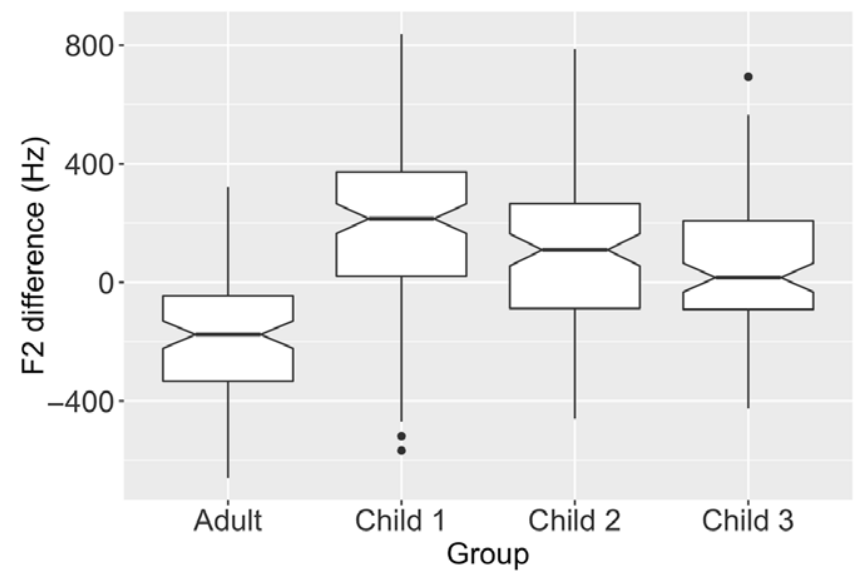

Figure 15 The F2 difference between /i/ in Dieb, Wiese 'lawn' and /e/ in /esen 'to read' calculated with (3) for adults and children in year 1 , year 2 and year 3 . 
$\left(t_{47.1}=7.8, p<.001\right.$ for adults and year 1 children; $t_{50.0}=5.5, p<.001$ for adults and year 2 children; $t_{52.6}=4.5, p<.001$ for adults and year 3 children).

\subsection{Diphthongs}

The first hypothesis to be tested was that children might monophthongise the opening diphthongs /ia ua/ because they are monophthongal /i $\mathrm{u} /$ in SG. The available words for this purpose were Fliege 'fly', Füße 'feet' for /ia/ and Schuh 'shoe' for /ua/. As Figure 16 shows there is no evidence to support this hypothesis. The second hypothesis was that the closing diphthongs would shift towards those in the standard. For this purpose, we tested whether FEUER and DREI which have the same /ai/ in WCB are beginning to split under the influence of SG in which they are, respectively, /OY aI/ and whether WCB DREI, STEIN which are /ai

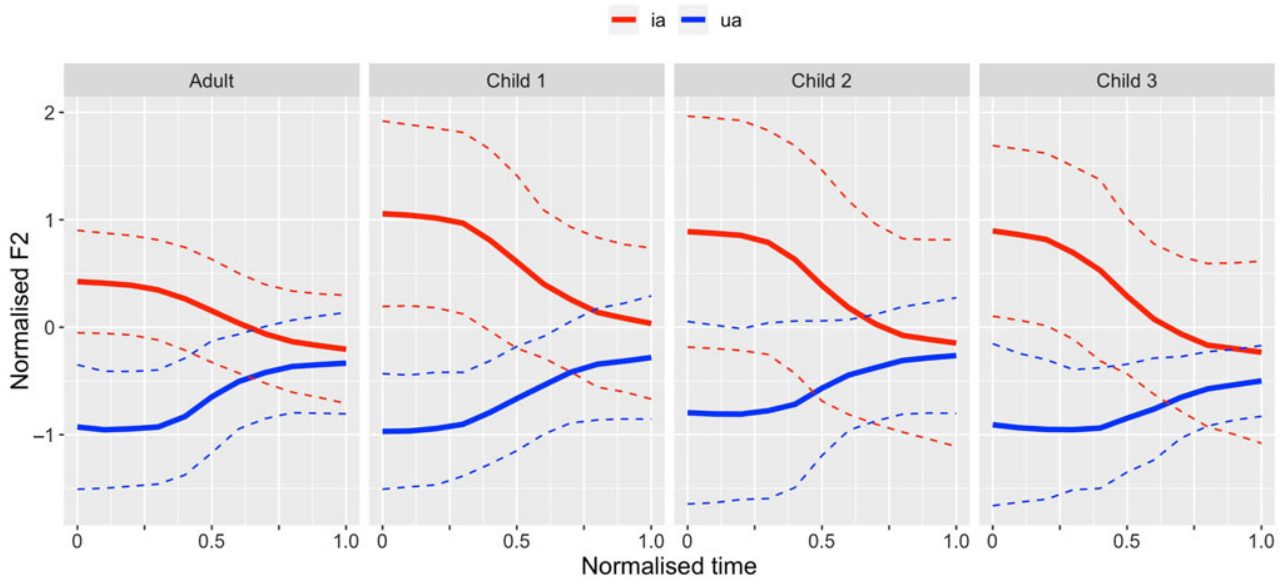

Figure 16 Time-normalised F2 trajectories of /ia ua/ diphthongs aggregated separately for adults, year 1, year 2 and year 3 children. Solid/dashed lines: trajectories of the mean and at 1.96 standard deviations from the mean, respectively.

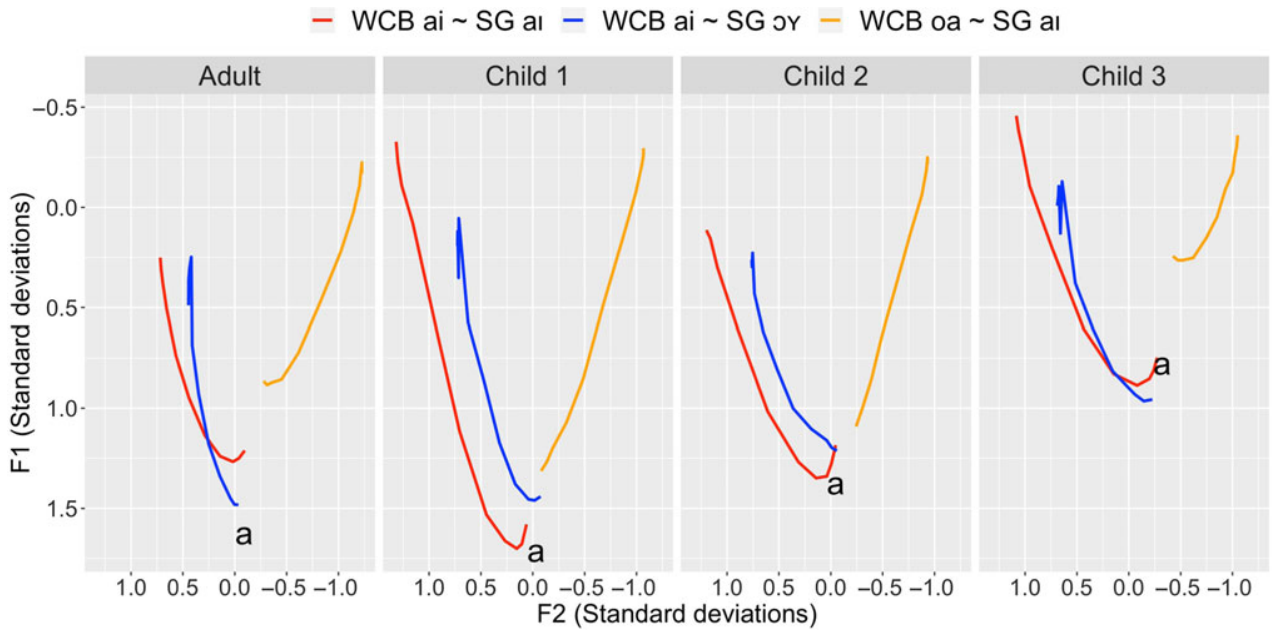

Figure 17 Aggregated F1 and F2 trajectories for three types of diphthongs in adults, year 1, year 2 and year 3 children as well as aggregates of /a/-vowels as reference. 
$\mathrm{oa} /$ are beginning to merge since these are both /aI/ in SG (Figure 3). The test was carried out for (i) drei 'three', Wein 'wine' (WCB /ai/ SG /ai/) (ii) Feuer 'fire', Häuser 'houses' (WCB /ai/ SG /oy/), and (iii) eins 'one', Leiter 'ladder', Stein'stonde', zwei 'two' (WCB /oa/ SG /aI/). There was no support for this type of influence of SG on WCB. That is, there is no evidence from Figure 17 for a greater merger of (i) and (iii) (Figure 17: red, orange) nor for a greater split between (i) and (ii) (Figure 17: red, blue) in children than in adults.

\section{Discussion}

The study has been concerned with establishing whether the vowels of West Central Bavarian are being influenced by those of Standard German. The question was addressed by documenting the known differences between the varieties in the vowels both phonologically and phonetically. Some of these differences were then used to predict the direction in which the vowels of WCB children and WCB adults might diverge, under the assumption that those of WCB children are influenced to a greater extent by the standard.

The analysis of WCB adults' speech showed many of the hallmarks of WCB that make it distinct from SG. These distinguishing WCB characteristics include in particular:

(6) a. A contrast in KABEL and GABEL between (a) an open central and (b) an open, or half-open rounded vowel (Figure 5).

b. The use of post-vocalic consonant length to distinguish V:C from VC: (Figure 8).

c. Few or minimal quality differences between vowels that contrast in tensity in SG (Figure 10, left panels).

d. Few or minimal quality differences between front vowels that contrast in rounding in SG (Figure 12, left panel).

e. A phonetic fronting relationship between $/ \mathrm{i} \mathrm{e} /$ that is different from that typically found in SG.

f. Opening diphthongs in FLIEGE and SCHUH that map to high SG monophthongs (Figure 16), (b) no observable quality differences between diphthongs in DREI and FEUER that are distinct in SG, and (c) a distinction between the diphthongs exemplified by DREI and STEIN that are non-distinct in SG (Figure 17, left panel).

g. High and mid-high diphthongs along a trajectory from back to front that map, respectively, to high and mid/low vowels before laterals in SG (Figure 6).

The children's vowels were undoubtedly WCB as they were characterised by all of the attributes sketched in the list in (6) above that had been found for adults. Thus, one of the main findings in this study is that the defining characteristics of WCB are being transmitted to the youngest generations, at least in a rural area like the one analysed here. But in line with other studies showing that German dialects are being influenced by the standard (Scheuringer 1990, Müller et al. 2011, Bukmaier et al. 2014, Kleber 2017), many aspects of the children's speech data showed a shift towards SG. The strongest shift was for $(6 a, b)$ above, i.e. the approximation of $/ \mathrm{p}$ a/ and the shortening of the post-vocalic long $/ \mathrm{s} /$. For both (6a) and (6b), there were adult/child differences as well as a longitudinal trend in which these differences were more marked for children recorded in their third than in their second than in their first year. The next strongest shift was for (6c) and (6d) that pointed to the development of SG tensity and SG rounding contrasts. Here there were adult/child differences but no longitudinal trend. The results for (6e), concerning whether the fronting relationship in /i e/ had changed, showed overall adult/child differences but no evidence for a longitudinal trend for this relationship to be increasingly reversed in children. There was no evidence that the children had shifted towards SG to a greater extent than adults in any of the diphthongs 
(refer to the characteristics in (6f) above). Finally, there were no innovations introduced by the children that were not in the direction of Standard German.

Studies in the last 20-30 years have documented a variety of factors that are likely to cause the sounds of a dialect (D1) to shift when it comes into contact with another dialect (D2). Although the literature on dialect contact is by no means equivalent to the bidialectal ${ }^{10}$ situation (Hazen 2001, Oschwald et al. 2018) analysed in the present study, it is interesting to consider whether the findings of the changes (in 6a-e above) and lack of change (in 6f) are consistent with the predictions and results from these studies on second dialect acquisition. A summary of the main findings by which the sounds of D1 may or may not be modified by D2 are as follows.

(7) a. Exceptionless features are acquired more easily. There is a large body of research showing that children are more likely to acquire the sounds of a new dialect if the change relating D1 and D2 apply to words with limited exceptions, i.e. if sounds from D2 are not conditioned by lexical, morphological, or phonological constraints (Payne 1980; Chambers 1992; Kerswill 1996; Nycz 2015, 2019) with respect to D1. For example, a British English speaker learning General American may readily adopt the American English production of an intervocalic / $t$ / as a flap because the context in which flaps occur is largely predictable. By contrast, Northern English speakers who have the same / $/$ / vowel exemplified by the lexical sets FOOT and STRUT might be less likely to acquire the $/ U \sim \Lambda$ / distinction that occurs in other varieties of English because of the complex (largely phonological) factors that condition the split (Wells 1982).

b. Mergers are more likely to be acquired than new contrasts. Some studies show that D2 contrasts that do not exist in D1 are either not acquired or acquired incompletely (Chambers 1992, Kerswill 1996, Evans \& Iverson 2007). According to Labov (1994), mergers are often changes from below (the level of consciousness) and so may be more readily acquired than splits if D2 does not make a contrast that exists in D1.

c. Saliency/awareness influences D2 acquisition. It has been repeatedly suggested (Trudgill 1986, Auer et al. 1998, Siegel 2010) that the shift towards D2 is influenced by whether sounds are salient and well-known markers of a dialect. Nycz (2013a, b) showed that Canadians who had moved to the northern United States shifted only minimally the raised nucleus of the diphthong in words like about precisely because this is known to be a typical marker of Canadian English (that is also commented upon in the media and by the public) that does not occur in most varieties of American English. In a longitudinal study of the '7-up' series, ${ }^{11}$ Sankoff (2004) suggests that the Northern England speakers were less inclined to adopt the vowel close to CV5 (/a/) in 'bath' that is a notable, salient marker of Southern English. Salience and its relationship to whether or not D1 shifts towards D2 may also be conditioned by the speaker's attitude towards the dialect that is being acquired (Niedzielski 1999 for related perception studies, Walker 2014; see also Hay \& Drager 2010, Jannedy \& Weirich 2014).

d. A sound in D2 is more likely to be acquired if it already exists in D1. Payne (1976, 1980) was among the first to suggest that a sound of D2 is more readily acquired if it

\footnotetext{
${ }^{10}$ The term 'bidialectism' is derived from bilingualism and describes the ability of speaking a basic dialect that diverges substantially from the corresponding standard language in addition to the (regionally coloured) standard.

${ }^{11}$ In the film series knowns as 7 and $U p$ the British filmmaker Michael Apted interviewed 14 seven-yearold children in 1963. He re-recorded a subset of this group every seven years, the latest including a majority of the members of the original group at age 42 in 1999.
} 
exaggerates a phonetic tendency that already exists in D1. Bigham (2010) showed that female Southern Illinois high school students' $[\mathrm{o} u$ ] that varied considerably along a front-back dimension became more retracted after contact with Northern students who had a retracted [o $\mathrm{u}]$. This idea is central to the cognitive-computational model of sound change developed in Harrington et al. (2018). In their model, a sound from dialect D1 is attracted towards D2 if the variation of the sound in D1 is in the direction of D2. For example, Harrington \& Schiel (2017) showed that D1 individuals (represented as computational agents) with a mostly retracted / $\mathrm{u} /$ that was also sometimes fronted though due to coarticulation, shifted towards a more fronted variant as a consequence of contact with D2 individuals who only had a fronted $/ \mathfrak{u} /$.

Could any of these four points (7a-d) explain why WCB children showed a greater tendency to shift towards SG on (6a-e) but not on (6f)? Complexity in the sense of (7a) is unlikely to explain the differences between (6a-e) and (6f). The structural relationships in Figure 3 do not suggest, for example, that the mapping of WCB /oa ai/ to SG/ai/ (in which there was no evidence of a shift towards SG) is any more or less complex than e.g. the mapping between $\mathrm{WCB} / \mathrm{i} /$ and SG /i I/ (where children did show a shift towards SG). Neither can (7b) provide any coherent explanation for the pattern of shifts towards SG. This is because while (7b) does predict the observed failure for $\mathrm{WCB} / \mathrm{ai} /$ to split into SG/aI $ə \mathrm{Y} /$ as well as the tendency of a merger of $/ \mathrm{p}$ a/ to $\mathrm{SG} / \mathrm{a} /(6 \mathrm{a})$, it is not compatible with the observed tendency for WCB children's /i/ to begin to split into an SG-like /i I/ (the characteristic in (6c) above) nor for WCB children's /e/ to show signs of splitting into an SG /e ø/ contrast (the characteristic in (6d) above).

With regard to (7c), we have already noted that /oa/ and the opening diphthongs /ia ua/ are markers of WCB that are commented upon by the media and public. Perhaps there was no shift towards SG because these diphthongs are such clear identifiers of WCB. However, this interpretation is inconsistent with the finding that the children showed a shift towards $\mathrm{SG}$ in both / $\mathrm{p} /(6 \mathrm{a})$ and in the rounding of front vowels (6e). Moreover, both WCB $/ \mathrm{p} /$ and the WCB production of unrounded vowels exemplified by VöGEL (Figure 3) are also known (and commented upon) markers of WCB. ${ }^{12}$

Finally, (7d) predicts sound change if SG characteristics already exist in WCB. The potential relevance of $(7 \mathrm{~d})$ to the observed shifts towards SG is as follows:

(8) a. As Figure 5 shows, the orientation and spread of $/ \mathrm{p} /$ towards $/ \mathrm{a} /$ is greater than in the other direction. In terms of the model of Harrington et al. (2018), /a/ (and by implication $\mathrm{SG} / \mathrm{a} /$ ) is an attractor for $\mathrm{WCB} / \mathrm{p} /$ (because the distribution of $\mathrm{WCB} / \mathrm{p} /$ already contains some variants that are quite /a/-like).

b. In a hypoarticulated/casual speaking style, long consonants are more likely to shorten than short consonants to lengthen (e.g. van Son \& Pols 1999). Thus, the shorter C in SG is an attractor for the long C: in WCB (which may tend to drift towards $\mathrm{C}$ in faster/hypoarticulated speaking styles).

c. In a hypoarticulated/casual speaking style, vowels are often centralised, i.e. are less peripheral (Lindblom 1990, van Bergem 1993, van Son et al. 2004). Thus, it can be expected that hypoarticulated WCB /i e/ shift in the direction of more centralised qualities. For this reason, $\mathrm{SG} / \mathrm{I} / \mathrm{which}$ is a centralised mid-high vowel is an attractor for $\mathrm{WCB} / \mathrm{i} /$ in SPINNE and $\mathrm{SG} / \varepsilon /$ for $\mathrm{WCB} / \mathrm{e} /$ in BETT.

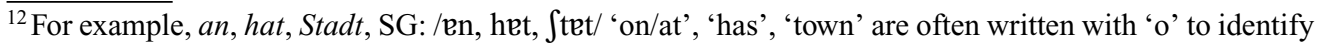
WCB as in E. Hürlimann's caricature of Bavarian Eahm schaug $\boldsymbol{o}$ (SG: ihm schau an, lit.: 'to him look at', i.e. 'look at him') or the song Sie hod mein' Style (mei' Stodt') by Isar Mafia. WCB front unrounded vowels in words exemplified by VÖGEL are sometimes written with 'e(e)' e.g. So neu und so schee!

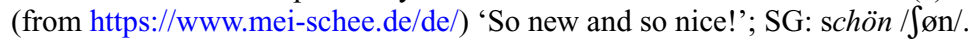


d. A similar explanation to that in $(8 \mathrm{c})$ can be made with regard to lip-rounding. It has been shown for SG (e.g. Hoole 1999, Figure 5 in Harrington et al. 2011) that $/ y \varnothing /$ have centralised and lowered tongue position relative to $/ \mathrm{i}$ e/. Thus, SG front rounded vowels are also attractors for WCB /i e/ in words exemplified by FÜSSE and BÖSE, respectively.

The findings in (7d) may also be relevant to account for the lack of shift towards SG in the opening and closing diphthongs noted in (6f) above:

(9) a. In a more hypoarticulated speaking style, high opening diphthongs may well monophthongise (e.g. Standard British English /puə, po/ 'poor'; Lindsey 2019) but not as far as we know towards vowels with CV1 and CV8 qualities that characterise SG WIESE and SCHUH. Thus, SG /i u/ are unlikely to be attractors for WCB /ia ua/.

b. There is no phonetic reason that we can think of why the phonetic orientation towards $\mathrm{SG} / \mathrm{oY} /$ should be greater for WCB /ai/ in FEUER than in WCB /ai/ in DREI. There is therefore no SG attractor to encourage WCB /ai/ in FEUER and in DREI to split into $\mathrm{SG} / \mathrm{oY} /$ and $\mathrm{SG} / \mathrm{aI} /$, respectively.

c. For a similar reason as in (9b), SG /ai/ cannot be an attractor for WCB /oa/ because there is no reason why a falling diphthong /oa/ (exemplified by STEIN) should be phonetically oriented towards a rising /ai/ diphthong.

The analysis points to the general conclusion that a shift was most likely for WCB sounds when variation is phonetically directed towards or encompasses those of SG. This is also the outcome that is predicted by the cognitive-computational model of sound change developed in Harrington et al. (2018). According to this model, a sound from a dialect D1 is an attractor for a sound from dialect D2, if the sound in dialect D2 is skewed towards that of D1. This model can be applied to the present data on the assumption that the phonetically quite tense vowel in WCB SPINNE can also be undershot and centralised in a more casual speaking style or faster speaking rate. Since the vowel in SG SPINNE is lax and more central than its WCB counterpart, then (because of undershoot/centralisation) WCB SPINNE encompasses variants that are already in the direction of its SG counterpart. Therefore, SG SPINNE acts as an attractor because WCB SPINNE is skewed towards it according to the model in Harrington et al. (2018). From another perspective, the reason why WCB children begin to make a split of $\mathrm{WCB} / \mathrm{i} /$ in the direction of SG /i I/ is because, when they hear SG speakers produce SPINNE with a lax /I/, WCB children consider it to be a possible (albeit outlier) form of WCB SPINNE. Following the exemplar model in which words and phonological knowledge are statistical generalisations over remembered speech signals (Johnson 1997, Pierrehumbert 2003), WCB children might then readily absorb perceived SG productions into their own cognitive representations of SPINNE. This does not happen for WCB /i/ in WIESE, because, even though WCB WIESE can no doubt also be reduced and centralised in hypoarticulated speech, these reduced and centralised forms are not skewed towards SG WIESE which is tense /i/. For a related reason, WCB /ai/ in both FEUER and FEIER did not split into SG /oY aI/ because the phonetic variation in WCB FEUER is unlikely to overlap very much with the phonetic range within which $\mathrm{SG} / \mathrm{oy} /$ is produced.

This type of change that has been observed in this study is sometimes called 'automatic' which Siegel (2010) contrasts with changes that are 'socially motivated, arising from an unconscious desire for social approval from one's interlocutors'. This first type of non-socially motivated, automatic change has also recently been found in the accents of (English-speaking) winterers isolated together in Antarctica for a prolonged period of time (Harrington et al. 2019) and in studies showing Canadians' tendency to unmerge COT/CAUGHT as a consequence of contact with speakers of New York City English which Nycz (2016) considers to be driven by 'automatic accommodative processes'. The basis for these types of automatic changes is likely to be spontaneous imitation (Delvaux \& Soquet 
2007) which can take place in the absence of any social motivation to do so (Nielsen 2011, 2014; Pardo et al. 2012). Imitation is the mechanism in episodic models and associated computational implementations (Wedel 2006, Harrington et al. 2018, Todd, Pierrehumbert \& Hay 2019) that causes memorised exemplars of words to be updated depending on the type of phonetic variation to which an interlocutor happens to be exposed. Trudgill (2008) reasons that New Zealand English in its earliest stages was shaped in particular by children's 'innate tendency to behavioural coordination' (see also Sebanz, Bekkering \& Knoblich 2006, Fowler et al. 2008), i.e. by an automatic, non-socially driven imitation of the range of spoken accents that they heard. We suggest that a similar kind of non-social, but probabilistic (rather than as in Trudgill 2008, deterministic) mechanism is likely to be the cause of the shift in children's WCB as a consequence of their greater contact to SG speakers compared with that of the older generation analysed here.

We emphasise that there are many caveats to these conclusions. In particular, the study is based on such a small number of words per condition. This applies in particular to the conclusions about open vowels (Section 3.4) that were based on only seven words, rounding (Section 3.5) based on only five words, and the relative positions of /e i/ (Section 3.6) based on only three words. The very limited scope of this study in this regard was a necessary consequence of combining an analysis of breadth across the WCB vowel/diphthong space with the practicalities of the limited recording time that could be allocated per child. Thus, the possibility must also be considered that we may be observing word by word diffusion (Phillips 1984, Trudgill 1986, Bybee 2002) rather than shifts to entire phonological categories.

\section{Acknowledgements}

The research was funded by the project InterAccent https://www.phonetik.uni-muenchen.de/ Forschung/interaccent/interAccent.html, which has received funding from the European Research Council (ERC) under the European Union's Horizon 2020 research and innovation programme (grant agreement No. 742289). We thank the children who participated, their parents who gave their consent and the schools, the Nikodem-Caro-Volksschule Hart/Wald and the Grundschule Burgkirchen, which let us use their facilities for testing for making this research possible. We further thank the $J I P A$ editor Jody Kreiman, the associate editor Alexei Kochetov, and three anonymous reviewers for their very helpful and constructive comments.

\section{Appendix A. Additional example words for correspondences between Standard German (SG) and West Central Bavarian (WCB) phoneme categories}

Words exemplifying the LEXICAL SETS for the SG-WCB correspondences shown in Figure 3.

\begin{tabular}{lll} 
SG & \multicolumn{2}{l}{ WCB } \\
y & ia & FÜSSE, Gemüse, Kühe, müde, süß \\
i & ia & FLIEGE, Brief, lieb, Lied, schießen \\
i & ea & IHM, ihnen, Riemen, verdienen, Wien \\
i & i & WIESE, Dieb, Kies, Vieh, Zwiebel \\
I & i & SPINNE, Liste, sitzen, Tisch, Winter \\
Y & i & SCHLÜSSEL, gesünder, Hütte, München, Stückchen \\
Y & u & DRÜCKEN, Brücke, hüpfen, nützen, zurück \\
u & u & HUND, Butter, lustig, Rutsche, Suppe \\
u & u & ZUG, Bluse, Hupe, Nudel, super \\
u & ua & SCHUH, Bruder, Fuß, Kuchen, Kuh \\
o & u & TROCKEN, Sommer, Sonne, Sonntag, umsonst \\
o & o & ROCK, Frosch, Loch, Post, Stock \\
o & o & HOSE, groß, Ofen, Rose, tot
\end{tabular}




$\begin{array}{lll}\varepsilon & \varepsilon & \text { SCHNECKE, Fett, schwächer, Stecken, wetten } \\ \varepsilon & \text { e } & \text { BETT, Hände, länger, Messer, Wetter } \\ \varepsilon & \text { a } & \text { MÄNNER, Ente, kämmen Lämmchen, Rettich } \\ \text { e } & \varepsilon & \text { BESEN, beten, Reh, Schnee, weh } \\ \text { e } & \text { e } & \text { LESEN, Kleber, Regen, Steg, Weg } \\ \varnothing & \varepsilon & \text { BÖSE, blöd, Größe, Höhe, stößen } \\ \varnothing & \text { e } & \text { VÖGEL, Möbel, mögen, möglich, schön } \\ \propto & \text { e } & \text { LÖFFEL, Frösche, Köche, können, Röcke } \\ \varepsilon: & \varepsilon & \text { TÄTER, Bräter, Fräse, gelähmt, später } \\ \varepsilon: & \text { a } & \text { KÄSE, Gläser, mähen, schämen, zäh } \\ \text { a } & \text { a } & \text { KABEL, Examen, Gas, Rahm, Spaß } \\ \text { a } & \text { p } & \text { GABEL, Glas, Hase, Laden, Nadel } \\ \text { e } & \text { a } & \text { PFANNE, Kamm, Klasse, Tasse, Katze } \\ \mathfrak{x} & \text { D } & \text { SACK, Gasse, lassen, Platz, Spatz } \\ \text { au } & \text { au } & \text { HAUS, Kraut, Laus, laut, Maus } \\ \text { au } & \text { a } & \text { BAUM, Daumen, glauben, kaufen, laufen } \\ \text { oy } & \text { a } & \text { BÄUME, räumen, streuen, träumen, versäumen } \\ \text { oy } & \text { ai } & \text { FEUER, Freude, Heu, Häuser, Teufel } \\ \text { aI } & \text { ai } & \text { DREI, Leim, weiß the colour), Wein, Zeit } \\ \text { aI } & \text { oa } & \text { STEIN, Ei, klein, Leiter, zwei } \\ \text { aI } & \text { ea } & \text { STEINE, Breite, breiter, heißer, kleiner } \\ \text { al } & \text { oi } & \text { WALD, alt, halt, kalt, Salz } \\ \text { ol } & \text { oi } & \text { HOLZ, soll, Stolz, voll, Wolke } \\ \varepsilon l & \text { oi } & \text { GELD, helfen, schnell, Welt, Zelt } \\ \text { ul/ul } & \text { ui } & \text { STUHL, Dult, Pulver, Schuld, Schule } \\ \text { Il } & \text { ui } & \text { BRILLE, Bild, gilt, Milch, will } \\ \text { il } & \text { ui } & \text { SPIEL, Petersilie, Stiel, viel, Ziel } \\ \text { yl } & \text { ui } & \text { GEFÜHL, Kanüle, Mühle, spülen, Stühle }\end{array}$

\section{Appendix B. Complete list of words recorded in the experiment}

Recorded words, their target vowels, and the total number of repetitions correctly produced by adults and by children in years 1, 2 and 3. Shading marks recorded words that were not part of the analysis in this study.

\begin{tabular}{|c|c|c|c|c|c|c|}
\hline Target vowel & Word & English translation & Adults & Children year 1 & Children year 2 & Children year 3 \\
\hline \multirow{4}{*}{$/ \mathrm{a} /$} & KLASSE & class & 77 & 50 & 56 & 53 \\
\hline & KÄSE & cheese & 77 & 37 & 22 & 18 \\
\hline & KABEL & wire & 83 & 68 & 65 & 61 \\
\hline & SÄGE & saw & 17 & 11 & 1 & 4 \\
\hline \multirow{4}{*}{$/ \mathfrak{p} /$} & GLAS & glass & 78 & 21 & 18 & 20 \\
\hline & SACK & sack & 68 & 29 & 22 & 14 \\
\hline & HASE & rabbit & 71 & 31 & 22 & 16 \\
\hline & Gabel & fork & 73 & 27 & 24 & 24 \\
\hline \multirow{5}{*}{ /i/ } & TISCH & table & 79 & 29 & 12 & 20 \\
\hline & DIEB & thief & 21 & 55 & 54 & 37 \\
\hline & WIESE & lawn & 79 & 68 & 52 & 57 \\
\hline & SPINNE & spider & 84 & 74 & 70 & 61 \\
\hline & SCHLÜSSEL & key & 25 & 3 & 4 & 2 \\
\hline
\end{tabular}




\begin{tabular}{|c|c|c|c|c|c|c|}
\hline Target vowel & Word & English translation & Adults & Children year 1 & Children year 2 & Children year 3 \\
\hline & HÜTTE & cabin & 53 & 4 & 5 & 2 \\
\hline & SCHÜLER & pupil & 30 & 34 & 29 & 27 \\
\hline & MüLL & waste & 72 & 74 & 68 & 63 \\
\hline \multirow{4}{*}{$/ \mathrm{u} /$} & SUPPE & soup & 82 & 72 & 70 & 64 \\
\hline & HUND & $\operatorname{dog}$ & 76 & 75 & 69 & 61 \\
\hline & BUtTER & butter & 82 & 72 & 71 & 62 \\
\hline & RUTSCHE & slide & 81 & 76 & 71 & 63 \\
\hline \multirow{4}{*}{$/ 0 /$} & HoSE & trousers & 83 & 73 & 68 & 62 \\
\hline & RosE & rose & 84 & 77 & 69 & 62 \\
\hline & Rock & skirt & 80 & 22 & 11 & 18 \\
\hline & STock & stick & 9 & 21 & 13 & 14 \\
\hline \multirow{5}{*}{$\mid \varepsilon /$} & SCHNECKE & snail & 84 & 73 & 71 & 58 \\
\hline & BETEN & to pray & 61 & 12 & 5 & 5 \\
\hline & SCHNEE & snow & 43 & 7 & 10 & 3 \\
\hline & BESEN & broom & 70 & 10 & 9 & 7 \\
\hline & REH & deer & 65 & 3 & 7 & 12 \\
\hline \multirow{5}{*}{ /e/ } & LÖFFEL & spoon & 83 & 22 & 14 & 15 \\
\hline & VöGEL & birds & 80 & 24 & 12 & 17 \\
\hline & LESEN & to read & 66 & 64 & 59 & 50 \\
\hline & Ветt & bed & 81 & 38 & 25 & 20 \\
\hline & MESSER & knife & 79 & 31 & 24 & 23 \\
\hline \multirow{7}{*}{ /ai/ } & WeISS & white & 37 & 38 & 41 & 43 \\
\hline & DREI & three & 84 & 72 & 67 & 61 \\
\hline & WEIN & wine & 82 & 62 & 58 & 59 \\
\hline & FEUER & fire & 84 & 19 & 14 & 16 \\
\hline & HÄUSER & houses & 83 & 14 & 14 & 15 \\
\hline & HEU & hay & 11 & 17 & 14 & 15 \\
\hline & $\mathrm{El}$ & egg & 71 & 14 & 8 & 9 \\
\hline \multirow{4}{*}{ /oa/ } & ZWEI & two & 82 & 35 & 22 & 23 \\
\hline & StelN & stone & 84 & 38 & 26 & 18 \\
\hline & LEITER & ladder & 83 & 13 & 17 & 17 \\
\hline & EINS & one & 84 & 41 & 21 & 23 \\
\hline \multirow{4}{*}{ /ia/ } & FLIEGE & fly & 79 & 26 & 19 & 20 \\
\hline & FÜSSE & feet & 80 & 26 & 17 & 12 \\
\hline & KIRCHE & church & 84 & 73 & 56 & 40 \\
\hline & LICHT & light & 11 & 5 & 1 & 4 \\
\hline \multirow{4}{*}{ /ua/ } & Sснин & shoe & 82 & 41 & 28 & 15 \\
\hline & FUTTER & fodder & 74 & 5 & 8 & 11 \\
\hline & SCHNUR & string & 30 & 48 & 41 & 31 \\
\hline & UHR & clock & 84 & 80 & 67 & 21 \\
\hline \multirow[t]{2}{*}{ /oi/ } & GELD & money & 43 & 26 & 15 & 20 \\
\hline & HOLZ & wood & 71 & 34 & 25 & 12 \\
\hline \multirow{3}{*}{ /ui/ } & STUHL & chair & 84 & 35 & 25 & 3 \\
\hline & BRILLE & glasses & 81 & 13 & 14 & 8 \\
\hline & SPIEL & game & 25 & 23 & 10 & 6 \\
\hline
\end{tabular}




\section{References}

Auer, Peter, Birgit Barden \& Beate Grosskopf. 1998. Subjective and objective parameters determining "salience" in long-term dialect accommodation. Journal of Sociolinguistics 2, 163-187.

Bailey, Guy, Tom Wikle, Jan Tillery \& Lori Sand. 1991. The apparent time construct. Language Variation and Change 3(3), 241-264.

Bannert, Robert. 1973. Zur Stimmhaftigkeit und Quantität in einem bairischen Dialekt (Working Papers 6). Lund: Lund University, Department of Linguistics and Phonetics.

Bannert, Robert. 1976. Mittelbairische Phonologie auf akustischer und perzeptorischer Grundlage. Ph.D. dissertation, Lund University.

Beddor, Patrice S. 1982. Phonological and phonetic effects of nasalization on vowel height. Ph.D. dissertation, University of Minnesota.

Besch, Werner. 1983. Entstehung und Ausprägung der binnensprachlichen Diglossie im Deutschen. In Werner Besch, Ulrich Knoop, Wolfgang Putschke \& Herbert E. Wiegand (eds.), Dialektologie: ein Handbuch zur deutschen und allgemeinen Dialektforschung, vol. 2., 1399-1411. Berlin: de Gruyter.

Bigham, Douglas S. 2010. Mechanisms of accommodation among emerging adults in a university setting. Journal of English Linguistics 38, 193-210.

Boersma, Paul \& David Weenink. 1992-2016. Praat: Doing phonetics by computer (Version 6.0.23). http://www.praat.org/. [Computer program]

Bose, Ines, Ursula Hirschfeld, Baldur Neuber \& Eberhard Stock. 2016. Einführung in die Sprechwissenschaft. Tübingen: Narr.

Bukmaier, Véronique, Jonathan Harrington \& Felicitas Kleber. 2014. An analysis of post-vocalic /s- $\int /$ neutralization in Augsburg German: Evidence for a gradient sound change. Frontiers in Psychology 5, 828.

Bybee, Joan. 2002. Word frequency and context of use in the lexical diffusion of phonetically conditioned sound change. Language Variation and Change 14, 261-290.

Capell, C. E. 1979. Transcription, vowel and consonant systems of Upper Bavarian dialect. Journal of the International Phonetic Association 9(1), 7-14.

Carignan, Christopher. 2018. Using naïve listener imitations of native speaker productions to investigate mechanisms of listener-based sound change. Laboratory Phonology: Journal of the Association for Laboratory Phonology 9(1), 18.

Chambers, J. K. 1992. Dialect acquisition. Language 68, 673-705.

Chambers, J. K. \& Peter Trudgill. 1998. Dialectology. Cambridge: Cambridge University Press.

Delvaux, Véronique \& Alain Soquet. 2007. The influence of ambient speech on adult speech productions through unintentional imitation. Phonetica 64, 145-73.

Draxler, Christoph \& Klaus Jaänsch. 2004. SpeechRecorder: A universal platform independent multichannel audio recording software. Proceedings of the Fourth International Conference on Language Resources and Evaluation, Lisbon, Portugal, 559-562.

Edwards, Jan \& Mary E. Beckman. 2008. Some cross-linguistic evidence for modulation of implicational universals by language-specific frequency effects in phonological development. Language Learning and Development 4(2), 122-156.

Evans, Bronwen G. \& Paul Iverson. 2007. Plasticity in vowel perception and production: A study of accent change in young adults. The Journal of the Acoustical Society of America 121, 3814-3826.

Fowler, Carol A., Michael J. Richardson, Kerry L. Marsh \& Kevin D. Shockley. 2008. Language use, coordination, and the emergence of cooperative action. In Armin Fuchs \& Viktor K. Jirsa (eds.), Understanding complex systems, 261-279. Berlin: Springer.

Hajek, John. 1997. Universals of sound change in nasalization. Oxford: Blackwell.

Harrington, Jonathan, Philip Hoole, Felicitas Kleber \& Ulrich Reubold. 2011. The physiological, acoustic, and perceptual basis of high back vowel fronting: Evidence from German tense and lax vowels. Journal of Phonetics 39, 121-131.

Harrington, Jonathan \& Florian Schiel. 2017. /u/-fronting and agent-based modeling: The relationship between the origin and spread of sound change. Language 93(2), 414-445. 
Harrington, Jonathan, Felicitas Kleber, Ulrich Reubold, Florian Schiel \& Mary E. Stevens. 2018. Linking cognitive and social aspects of sound change using agent-based modeling. Topics in Cognitive Science $10(4), 1-21$.

Harrington, Jonathan, Michele Gubian, Mary E. Stevens \& Florian Schiel. 2019. Phonetic change in an Antarctic winter. The Journal of the Acoustical Society of America 146, 3327-3332.

Hay, Jennifer \& Katie Drager. 2010. Stuffed toys and speech perception. Linguistics 48, 865-892.

Hazen, Kirk. 2001. An introductory investigation into bidialectalism. University of Pennsylvaia Working Papers in Linguistics 7, 85-99.

Hoole, Philip. 1987. Bite-block speech in the absence of oral sensibility. Proceedings of the 13th International Conference of Phonetic Sciences (ICPhS XIII), Stockholm, vol. 4, 16-19.

Hoole, Philip. 1999. On the lingual organization of the German vowel system. The Journal of the Acoustical Society of America 106, 1020-1032.

Institut für Demoskopie Allensbach (ed.). 1998. Allensbacher Berichte. Bayerisch hören viele gern (22). Allensbach: Institut für Demoskopie.

Institut für Demoskopie Allensbach (ed.). 2008. Allensbacher Berichte. Auch außerhalb von Bayern wird Bayerisch gern gehört (4). Allensbach: Institut fuär Demoskopie.

Jannedy, Stefanie \& Melanie Weirich. 2014. Sound change in an urban setting: Category instability of the palatal fricative in Berlin. Laboratory Phonology: Journal of the Association for Laboratory Phonology $5,91-122$.

Johnson, Keith. 1997. Speech perception without speaker normalization: An exemplar model. In Keith Johnson \& John W. Mullennix (eds.), Talker variability in speech processing, 145-165. San Diego, CA: Academic Press.

Kerswill, Paul. 1996. Children, adolescents, and language change. Language Variation and Change 8, 177-202.

Kerswill, Paul \& Ann Williams. 2000. Creating a New Town koine: Children and language change in Milton Keynes. Language in Society 29, 65-115.

Kisler, Thomas, Uwe Reichel \& Florian Schiel. 2017. Multilingual processing of speech via web services. Computer Speech \& Language 45, 326-347.

Kleber, Felicitas. 2011. Incomplete neutralization and maintenance of phonological contrasts in varieties of Standard German. Ph.D. dissertation, Ludwig-Maximilians-University, Munich.

Kleber, Felicitas. 2017. Complementary length in vowel-consonant sequences: Acoustic and perceptual evidence for a sound change in progress in Bavarian German. Journal of the International Phonetic Association 50, 1-22.

Kohler, Klaus J. 1995. Einfuährung in die Phonetik des Deutschen, 2nd edn. Berlin: Schmidt.

König, Werner. 1994. Dtv-Atlas Deutsche Sprache. München: Deutscher Taschenbuchverlag.

Kufner, Herbert. L. 1957. History of the Middle Bavarian vocalism. Language 33(4), 519-529.

Kufner, Herbert L. 1960. History of the Central Bavarian obstruents. Word 16(1), 11-27.

Kuznetsova, Alexandra, Per B. Brockhoff \& Rune HB Christensen. 2017. lmerTest package: Tests in linear mixed effects models. Journal of Statistical Software 82(13), 1-26.

Labov, William. 1994. Principles of linguistic change, vol. 1: Internal factors. Oxford: Blackwell.

Labov, William. 2007. Transmission and diffusion. Language 83, 344-387.

Lenth, Russell. 2019. Emmeans: Estimated marginal means, aka least-squares means. R package version 1.3.4. https://CRAN.R-project.org/package $=$ emmeans.

Leopold, Werner F. 1959. The decline of German dialects. Word 15(1), 130-153.

Lindblom, Björn. 1990. Explaining phonetic variation: A sketch of the H\&H theory. In William J. Hardcastle \& Alain Marchal (eds.), Speech production and speech modelling, 403-439. Dordrecht: Kluwer.

Lindblom, Björn \& Johan Sundberg. 1971. Acoustical consequences of lip, tongue, jaw, and larynx movement. The Journal of the Acoustical Society of America 50, 1166-1179.

Lindsey, Geoff. 2019. English after RP: Standard British pronunciation today. London: Palgrave MacMillan.

Lobanov, Boris M. 1971. Classification of Russian vowels spoken by different speakers. The Journal of the Acoustical Society of America 49(2B), 606-608. 
Mansell, Phil. 1973. A sketch of Bavarian vowel phonology. Forschungsberichte des Instituts für Phonetik und sprachliche Kommunikation der Universität München 1, 187-208.

Merkle, Ludwig. 1976. Bairische Grammatik. München: Deutscher Taschenbuchverlag.

Mooney, Shannon. 2020. Child acquisition of sociolinguistic variation. Ph.D. dissertation, Georgetown University.

Müller, Viola, Jonathan Harrington, Felicitas Kleber \& Ulrich Reubold. 2011. Age-dependent differences in neutralization of the intervocalic voicing contrast: Evidence from an apparent-time study on East Franconian. Twelfth Annual Conference of the International Speech Communication Association (Interspeech 2011), Florence, 633-636.

Nardy, Aurélie, Jean-Pierre Chevrot \& Stephanie Barbu. 2014. Sociolinguistic convergence and social interactions within a group of pre-schoolers: A longitudinal study. Language Variation and Change 26, 273-301.

Niedzielski, Nancy. 1999. The effect of social information on the perception of sociolinguistic variables. Journal of Language and Social Psychology 18, 1-18.

Nielsen, Kuniko. 2011. Specificity and abstractness of VOT imitation. Journal of Phonetics 39, 132-142.

Nielsen, Kuniko. 2014. Phonetic imitation by young children and its developmental changes. Journal of Speech Language and Hearing Research 57, 2065-2075.

Nycz, Jennifer. 2013a. Changing words or changing rules? Second dialect acquisition and phonological representation. Journal of Pragmatics 52, 49-62.

Nycz, Jennifer. 2013b. New contrast acquisition: Methodological issues and theoretical implications. English Language and Linguistics 17, 325-357.

Nycz, Jennifer. 2015. Second dialect acquisition: A sociophonetic perspective. Language and Linguistics Compass 9, 469-482.

Nycz, Jennifer. 2016. Awareness and acquisition of new dialect features. In Anna M. Babel (ed.), Awareness and control in sociolinguistic research, 62-79. Cambridge: Cambridge University Press.

Nycz, Jennifer. 2019. Linguistic and social factors favoring acquisition of contrast in a new dialect. Proceedings of the 19th International Congress of Phonetic Sciences (ICPhS XIX), Melbourne, $1480-1484$.

Oschwald, Jessica, Alisa Schättin, Claudia C. Von Bastian \& Alessandra S. Souza. 2018. Bidialectalism and bilingualism: Exploring the role of language similarity as a link between linguistic ability and executive control. Frontiers in Psychology 9, 1997.

Pardo, Jennifer S., Rachel Gibbons, Alexandra Suppes \& Robert M. Krauss. 2012. Phonetic convergence in college roommates. Journal of Phonetics 40, 190-197.

Pascoe, R. G. 1981. The phonology of Upper Bavarian: Some observations. Journal of the International Phonetic Association 11(2), 75-77.

Payne, Arvilla C. 1976. The acquisition of the phonological system of a second dialect. Ph.D. dissertation, University of Pennsylvania.

Payne, Arvilla C. 1980. Factors controlling the acquisition of the Philadelphia dialect by out-of-state children. In William Labov (ed.), Locating language in time and space 143-178. New York: Academic Press.

Phillips, Betty S. 1984. Word frequency and the actuation of sound change. Language 60, 320-342.

Pierrehumbert, Janet B. 2003. Phonetic diversity, statistical learning, and acquisition of phonology. Language and Speech 46(2-3), 115-154.

Reiffenstein, Ingo. 1976. Primäre und sekundäre Unterschiede zwischen Hochsprache und Mundart: überlegungen zum Mundartenabbau. Klagenfurt: Heyn.

Rein, Kurt. 1974. Die mittelbairische Liquiden-Vokalisierung. Zeitschrift für Dialektologie und Linguistik 41(1), 21-37.

Rowley, Anthony R. 2011. Bavarian: Successful dialect or failed language? In Joshua A. Fishman \& Ofelia García (eds.), Handbook of language and ethnic identity: The success-failure continuum in language and ethnic identity efforts, vol. 2, 299-309. New York: Oxford University Press.

Rues, Beate, Beate Redecker, Evelyn Koch, Uta Wallraff \& Adrian P. Simpson. 2007. Phonetische Transkription des Deutschen, 288-293. Tübingen: Narr. [A workbook with CD]

Sampson, Rodney. 1999. Nasal vowel evolution in Romance. Oxford: Oxford University Press. 
Sankoff, Gillian. 2004. Adolescents, young adults, and the critical period: Two case studies from "Seven Up". In Carmen Fought (ed.), Sociolinguistic variation: Critical reflections, 121-139. Oxford: Oxford University Press.

Scheuringer, Hermann. 1990. Sprachentwicklung in Bayern und österreich: eine Analyse des Substandardverhaltens der Städte Braunau am Inn (österreich) und Simbach am Inn (Bayern) und ihres Umlandes. Hamburg: Buske.

Schikowski, Robert. 2009. Die Phonologie des Westmittelbairischen. Master's thesis, LudwigMaximilians-University, Munich. https://doi.org/10.5282/ubm/epub.10991.

Schmidt, Wilhelm. 2000. Geschichte der deutschen Sprache, 8th edn. Stuttgart: S. Hirzel.

Sebanz, Natalie, Harold Bekkering \& Günther Knoblich. 2006. Joint action: Bodies and minds moving together. Trends in Cognitive Sciences 10, 70-76.

Seiler, Guido. 2009. Sound change or analogy? Monosyllabic lengthening in German and some of its consequences. The Journal of Comparative Germanic Linguistics 12(3), 229-272.

Siegel, Jeff. 2010. Second dialect acquisition. Cambridge: Cambridge University Press.

Stör, Bernhard. 1999. Die mundartlichen Verhältnisse in der Region Muänchen, vol. 1. Frankfurt am Main: Peter Lang.

Todd, Simon, Janet B. Pierrehumbert \& Jennifer Hay. 2019. Word frequency effects in sound change as a consequence of perceptual asymmetries: An exemplar-based model. Cognition 185, 1-20.

Trudgill, Peter. 1986. Dialects in contact. Oxford: Blackwell.

Trudgill, Peter. 2008. Colonial dialect contact in the history of European languages: On the irrelevance of identity to new-dialect formation. Language in Society 37(2), 241-254.

Vaissiére, Jaqueline. 2009. Articulatory modeling and the definition of acoustic-perceptual targets for reference vowels. The Chinese Phonetics Journal 2, 22-33. [Also available at: https://halshs.archivesouvertes.fr/halshs-00676256/document.]

Van Bergem, Dick R. 1993. Acoustic vowel reduction as a function of sentence accent, word stress, and word class. Speech Communication 12, 1-23.

Van Son, Rob, Olga Bolotova, Mietta Lennes \& Louis C. Pols. 2004. Frequency effects on vowel reduction in three typologically different languages (Dutch, Finnish, Russian). Proceedings of the 8th International Conference on Spoken Language Processing (Interspeech 2004), Korea, 1277-1280.

Van Son, Rob \& Louis C. Pols. 1999. An acoustic description of consonant reduction. Speech Communication 28, 125-140.

Veith, Werner H. 2005. Soziolinguistik: Ein Arbeitsbuch, 2nd edn. Tübingen: Narr.

Vollmann, Ralf, Thorsten Seifter, Bettina Hobel \& Florian Pokorny. 2015. /1/-Vokalisierung in der Steiermark. JournaLIPP 4, 13-25.

Walker, Abby. 2014. Crossing oceans with voices and ears: Second dialect acquisition and topic-based shifting in production and perception. Ph.D. dissertation, The Ohio State University.

Wardhaugh, Ronald \& Janet M. Fuller. 2015. An introduction to sociolinguistics, 7th edn. Chichester: Wiley Blackwell.

Wedel, Andrew B. 2006. Exemplar models, evolution and language change. The Linguistic Review 23, 247-274.

Weinreich, Uriel, William Labov \& Marvin Herzog. 1968. Empirical foundations for a theory of language change. In Windfred P. Lehmann \& Yakov Malkiel (eds.), Directions for historical linguistics, 95-195. Austin, TX: The University of Texas Press.

Wells, John C. 1982. Accents of English, vol. 1: An introduction. Cambridge: Cambridge University Press.

Wiese, Richard. 1996. The phonology of German. Oxford: Oxford University Press.

Wiesinger, Peter. 1990. The Central and Southern Bavarian Dialects in Bavaria and Austria. In Charles V. J. Russ (ed.), The dialects of Modern German, 438-519. London: Routledge.

Winkelmann, Raphael, Jonathan Harrington \& Klaus Jänsch. 2017. EMU-SDMS: Advanced speech database management and analysis in R. Computer Speech \& Language 45, 392-410.

Zehetner, Ludwig. 1978. Kontrastive Morphologie: Bairisch/Einheitssprache. In Ulrich Ammon, Ulrich Knoop \& Ingulf Radtke (eds.), Grundlagen einer dialektorientierten Sprachdidaktik, 313-331 Basel: Beltz.

Zehetner, Ludwig. 1985. Das bairische Dialektbuch. München: C. H. Beck.

Zehetner, Ludwig. 1989. Die bairische Mundart in Bayern. München: C. H. Beck. 